\title{
Integration of STI and HIV/AIDS with MCH-FP services: A case study of the Busoga Diocese Family Life Education Program, Uganda
}

Joy Mukaire

Florence Kalikwani

Baker Ndugga Maggwa

Population Council

Follow this and additional works at: https://knowledgecommons.popcouncil.org/departments_sbsr-rh

Part of the Family, Life Course, and Society Commons, International Public Health Commons, and the Maternal and Child Health Commons

How does access to this work benefit you? Let us know!

\section{Recommended Citation}

Mukaire, Joy, Florence Kalikwani, and Baker Ndugga Maggwa. 1997. "Integration of STI and HIV/AIDS with $\mathrm{MCH}-\mathrm{FP}$ services: A case study of the Busoga Diocese Family Life Education Program, Uganda," Africa OR/TA Project II. Nairobi: Population Council. 
January 1997

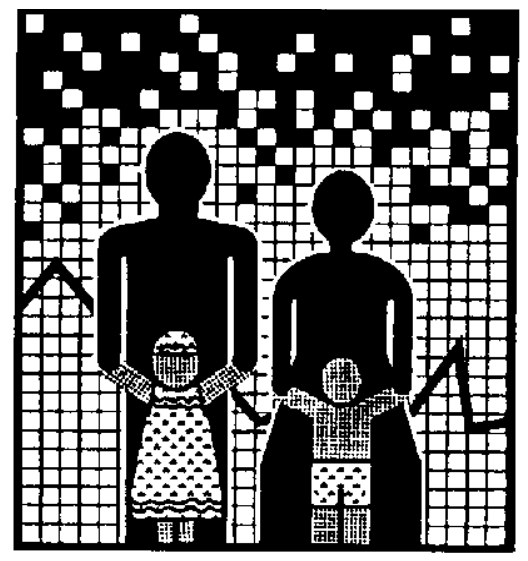

OPERATIONS

RESEARCH

TECHNICAL ASSISTANCE

AFRICA PROJECT II

THE POPULATION COUNCIL

Integration of STI and HIV/AIDS with MCH-FP Services:

A Case Study of the Busoga Diocese Family

Life Education Program, Uganda

Busoga Diocese Family Life Education Program

Joy Mukaire

Florence Kalikwani

The Population Council

Baker Ndugga Maggwa 


\section{The Population Council}

The Population Council seeks to help improve the well-being and reproductive health of current and future generations around the world and to help achieve a humane, equitable, and sustainable balance between people and resources. The Council analyzes population issues and trends; conducts biomedical research to develop new contraceptives; works with public and private agencies to improve the quality and outreach of family planning and reproductive health services; helps governments to influence demographic behaviour; communicates the results of research in the population field to appropriate audiences; and helps build research capacities in developing countries. The Council, a nonprofit, nongovernmental research organization established in 1952, has a multinational Board of Trustees; its New York headquarters supports a global network of regional and country offices.

\section{Africa OR/TA Project II}

The overall objective of the Africa OR/TA Project II is to broaden understanding of how to improve family planning services in Sub-Saharan Africa, and to apply operations research and technical assistance to improve services by:

- $\quad$ increasing access to a full range of family planning services and methods;

- $\quad$ developing service delivery strategies that are client-oriented and acceptable to various population groups:

- $\quad$ improving the operations of programs to make them more efficient and financially sustainable;

- $\quad$ improving the quality of services:

- $\quad$ strength ening the capabilities family planning program managers to use operations research to diagnose and solve service delivery problems.

This case study was supported by the Population Council's Africa Operations Research and Technical Assistance Project II, Project No. 936-3030, and by the Population Council's Cooperative Agreement No. CCP-3050-A-O0-4013-00, both funded by the United States Agency for International Development (USAID). 


\section{Acknowledgements}

This study was undertaken with substantial input from many people whose assistance is gratefully acknowledged. Special thanks go to the clients for agreeing to participate in the study, and to the service providers, administration staff and FLEP Board of management for the support they gave to the study team. Pathfinder International, through financial support from USAID, has consistently supported the Family Life Education Program's efforts to integrate its services by providing high quality technical assistance for all aspects of the integration process.

The Population Council and Pathfinder International are cooperating partners in a regional initiative to address FP/STI service integration. This initiative is coordinated by the USAID Regional Economic Development Services Office for East and Southern Africa (REDSO/ESA) with funding from USAID's Africa Bureau. Several members of this team have also contributed to the development and implementation of this case study: Elizabeth Lule at Pathfinder International; Richard Sturgis, Sophia Ladha and Victoria Wells at REDSO/ESA; and Lenni Kangas at the USAID Africa Buruea,

Washington. 


\section{ACRONYMS}

$\begin{array}{ll}\text { AIC } & \text { AIDS Information Center } \\ \text { AIDS } & \text { Acquired Immune Deficiency Syndrome } \\ \text { AIDSCAP } & \text { AIDS Control and Prevention Project } \\ \text { ANC } & \text { Antenatal Care } \\ \text { BCG } & \text { Bacilli Calmette Guerin } \\ \text { CBD } & \text { Community-based Distributer } \\ \text { CPR } & \text { Contraceptive Prevalence Rate } \\ \text { CYP } & \text { Couple Years of Protection } \\ \text { CWF } & \text { Child Welfare } \\ \text { DHS } & \text { Demographic Health Survey } \\ \text { DISH } & \text { Delivery of Improved Services for Health Project } \\ \text { DPT } & \text { Diphtheria Pertussis and Tetanus Vaccine } \\ \text { EPI } & \text { Expanded Program for Immunization } \\ \text { EZE } & \text { Evangelische Zeutralastelle fur Eutwicklishelfe } \\ \text { FLEP } & \text { Family Life Education Project } \\ \text { FPAU } & \text { Family Planning Association of Uganda } \\ \text { FP } & \text { Family Planning } \\ \text { FPIA } & \text { Family Planning International Assistance Project } \\ \text { HIV } & \text { Human Immunodeficiency Virus } \\ \text { IEC } & \text { Information, Education and Communication } \\ \text { IUD } & \text { Intrauterine Device } \\ \text { MCH } & \text { Maternal and Child Health } \\ \text { MCS } & \text { Mkomani Clinic Society } \\ \text { MOR } & \text { Ministry of Health } \\ \text { MRSDP } & \text { Multi-sectoral Rural Development Program } \\ \text { NACP } & \text { National AIDS Control Program } \\ \text { NGO } & \text { Non Governmental Organization } \\ \text { OR/TA } & \text { Operations Research/Technical Assistance } \\ \text { REDSO } & \text { Regional Economic Development Services Office } \\ \text { PID } & \text { Pelvic Inflammatory Disease } \\ \text { STD } & \text { Sexually Transmitted Disease } \\ \text { STI } & \text { Sexually Transmitted Infection } \\ \text { TASO } & \text { The AIDS Support Organization } \\ \text { TFR } & \text { Total Fertility Rate } \\ \text { USAID } & \text { United States Agency for International Development } \\ \text { VDRL } & \text { Venereal Disease Research Laboratory } \\ \text { VHW } & \text { Village Health Worker } \\ \text { WHO } & \text { World Health Organization } \\ & \end{array}$




\section{Table of Contents}

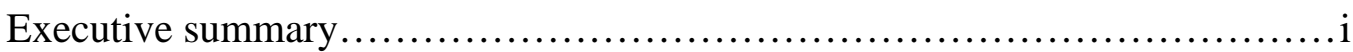

Background........................................................

The Family Life Education Project........................................2

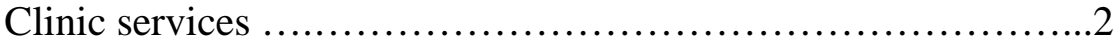

Community-based services.....................................

Integrating STI, HIV/AIDS and MCH/FP services............................

Reason for integrating STI, HIVIAIDS and MCH-FP services...........4

Activities undertaken by FLEP to help the integration process............4

The Family Life Education Project Integration Model.................5

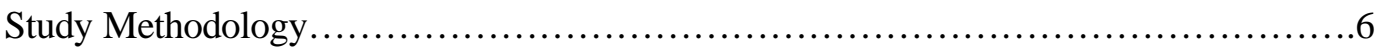

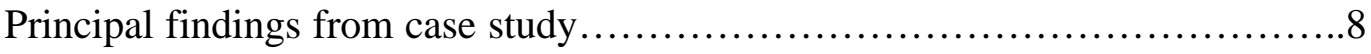

Preparedness of basic infrastructure to provide $\mathrm{MCH} / \mathrm{FP}$,

STI and HIV/AIDS services...............................8

Accessibility of services...............................10

Service provider preparedness to provide MCHIFP

and STI and/or HIV/AIDS services....................................... 11

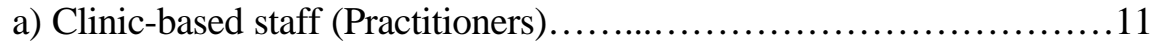

b) Village health workers........................................12

Implementation of the Integration Model.......................................... 14

a) STD and HIVIAIDS risk assessment for clients....................14

c) Informing clients about STD and HIV/AIDS......................17

d) Managing clients with STDs and HIV/AIDS ........................18

e) Contact tracing and follow-up.................................... 20

Need for contraceptive services among $\mathrm{MCH}$ clients............................... 21

Need for STI and HIVIAIDS Services................................................ 22

Effect of adding STI and HIVIAIDS service to MCH/FP services......................24

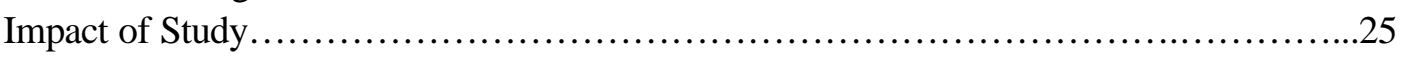




\section{Executive summary}

Introduction: The Family Life Education Project (FLEP) was started in 1986 by the Busoga Diocese of the Anglican Church of Uganda with assistance from the Pathfinder International. The project provides integrated MCH, FP, STD and HIV/AIDS services to more than 500,000 persons through 48 clinics and 162 trained village health workers. Each clinic serves an estimated 11,000 persons living in a geographically defined area called a sub-Parish. Each sub-Parish has a health subcommittee selected by the community which is responsible for hiring the clinic staff, identifying the village health workers, mobilizing resources from the community for salaries of the clinic staf \{ purchase of consumable supplies, construction and maintenance of the physical infrastructures.

In 1994 , the clinics provided family planning services to 26,429 clients $(52 \%$ were new clients) and treated 2160 clients for STDs. During the same period, the VHWs provided family planning services to 28, 267 clients (47\% were new clients) and reached 123, 229 and 88,238 clients with IEC activities through home visits and public meetings, respectively. These data suggest that the program is reaching a large number of clients through the clinic and community based approaches.

The methodology used for the case study embraced four activities: Review of available data and reports, in-depth interviews with management team, a modified Situation Analysis and guided group discussions.

Community Participation: The backbone of the project is the community involvement and participation. To ensure that the community is able to participate in the design and management of the project activities, all members of the health subcommittees have been trained in community mobilization, basic financial management and administrative procedures. The subcommittee members have also been trained in the basic concepts of family planning, STDs and HIV/AIDS. This investment in ensuring community participation has led to the following achievements;

- $\quad$ Through the cost recovery program managed by these subcommittees, communities have been able to raise adequate funds to pay salaries for the clinic based staff and provide some basic drugs and supplies for the clinics.

- With assistance from Pathfinder International, the subcommittees have been able to mobilize community resources to construct modem, user friendly and permanent structures for their clinics. At the time of the case study 25 sub-Parishes had completed building the permanent structures while the rest were at various stages of construction.

\section{Preparedness of facilities to provide integrated services:}

- Many clinics still operate in semi-permanent structures that do not provide adequate privacy, good client flow and are difficult to keep free of dust. Being in a rural area the majority of the clinics do not have access to adequate sources of light and water.

- $\quad$ Basic equipment and supplies required to provide good quality MCH, FP, STD and HIV/AIDS services using the integrated approach are lacking at many of the facilities. 
- Many facilities did not have access to appropriate sterilizing equipment, waste disposal facilities, sluice rooms for handling contaminated instruments/materials or sharps disposal containers.

- $\quad$ The program has developed culturally appropriate songs and drama to be used for group IEC activities but written materials for use during individual and group counselling were lacking at most facilities and many of the VHWs did not have any of these materials.

- $\quad$ Although family planning, HIV/AIDS counselling, STD services are available daily at all the 49 project clinics, antenatal and child welfare services are available only once a week at 15 and 33 clinics, respectively. This is due to lack of trained staff, necessary equipment like EPI refrigerators and supplies at most of these clinics.

- $\quad$ Apart from family planning, the other services (antenatal, child welfare, STD and HIV/AIDS) are poorly advertised at the clinics.

The findings from the study suggest that many of the clinics need further strengthening in order to provide good quality MCH, FP, STD and HIVIAIDS services using an integrated approach.

\section{Staff Preparedness to provide integrated services:}

- $\quad$ The project had 48 clinic staff (called practitioners) and 162 village health workers who had received various levels of training in the provision of MCH, FP, STD and HIV/AIDS services. This has been mainly through in-house seminars with assistance from TASO and AIC. More recently the DISH project has also assisted with the training of service providers in the project.

- $\quad$ Clinic staff are now expected to provide MCLI, FP, STD and HIV/AIDS services using the integrated approach yet few have had refresher training in antenatal, postnatal and child welfare. The FLEP has started addressing this with assistance from the DISH project and so far seven practitioners have attended a refresher course on antenatal, child welfare and postnatal care.

- $\quad$ The training in STD management has focussed mainly on using the syndromic approach to diagnose and decide treatment. Most of the service providers had not been trained in carrying out risk assessment and screening for STDs and HIV/AIDS.

- The program developed a diagnostic checklist to be used by clinic staff to screen all MCH/FP clients for STDs, but few service providers were using or following the instructions in the checklist.

- $\quad$ Guidelines for managing STDs were developed by the Ministry of Health in 1993 yet most clinic staff did not know of their existence and as such were not following them when managing clients with STDs. 
- There is only one practitioner at each of the clinics who is expected to provide MCH, FP, STD, HIV/AIDS and other curative services. The same service provider supervises the village health workers in the clinics catchment area. Although the family planning clients may not be many the same provider has to deal with the large number of clients seeking other services leaving them with little time to carry out risk assessment and provide adequate counselling for individual clients.

- $\quad$ The practitioners and village health workers are all well known and respectable members of the communities they serve. Some of them are even related to the clients they provide services to. This has presented some difficulties for the staff when dealing with sensitive issues like clients sexual behaviour and history of STDs.

\section{Implementation of the integration model:}

- Few clients receiving MCH/FP services from the project clinics were asked about or volunteered information on the known risk factors for STDs and HIV/AIDS. This may be due to the difficulties in communicating about sexual behaviour and STDs reported by both the clients and service providers. Large client loads and lack of privacy durinG the clinic sessions are other reasons.

- History taking and clinical examination for new family planning clients was not always done according to the diagnostic checklist provided to clinic staff by the project and the National Family Planning Guidelines.

- $\quad$ Clients requiring HIV, syphilis and other laboratory tests are referred to other institutions for testing. However, none of the clients receiving antenatal care during the study period were referred for syphilis testing.

- $\quad$ Most of the clients receiving MCH/FP services receive basic counselling on STDs and HIV/AIDS. However, less than half the clients counselled are informed about risk factors, symptoms, signs, complications and modes of transmission of STDs and HIV/AIDS.

- $\quad$ Service providers are expected to follow the STD treatment guidelines and algorithms prepared by the National STD Control Program but most of the clinics did not have the drugs recommended by these guidelines.

- $\quad$ Partner notification and treatment for STDs is a major problem for the program. The importance of partner notification and treatment is rarely discussed with clients who get counselled about STDs and HIV/AIDS. Many of the clients interviewed said that they feel uncomfortable discussing their sexual behaviour and STDs with their partners

The quality of services provided by the program is affected by the availability of an appropriate physical infrastructure, adequate equipment and supplies and the level of preparedness of the service providers. All these were found to need some improvements. 


\section{Need for family planning services among clients receiving MCH services at the clinics:}

- The program is reaching many of the clients receiving MCH services at the clinics with messages on family planning through posters and group health talks.

- $\quad$ Few of the clients receiving $\mathrm{MCH}$ services are asked about or volunteer information that would help in determining their family planning needs by the service provider. Even when information suggesting that a client needs family planning is available the staff do not always take advantage of it to provide the services to these clients.

\section{Need for STD and HIV/AIDS services:}

- $\quad$ Most of the women receiving MCH/FP services from the clinics do not know the signs and symptoms associated with STDs and HIVIAIDS. Womens' ability to recognize when they have an infection is important in a program that relies entirely on the syndromic approach to diagnose and treat STDs.

- When clients were informed about the signs and symptoms associated with STDs, more than one-half were able to recall having experienced at least one such symptom in the past year. This finding suggests that educating women about symptoms and signs of STDs may result in many of them recognizing these infections and seeking treatment.

- Using risk assessment, screening and the syndromic approach staff were observed to identify and treat $27 \%$ of the clients receiving MCHIFP services at the clinics for asymptomatic STDs. These data suggest that many $\mathrm{MCH} / \mathrm{FP}$ clients have asymptomatic infections that can be identified when services are provided using an integrated approach.

- $\quad$ Most of the clients considered themselves at risk for STDs and HIVIAIDS. They attributed this risk to the unknown sexual behaviour of their partners.

\section{Effect of adding STD and HIV/AIDS services on utilization of MCH/FP services:}

- The available service statistics show an increase in the number of $\mathrm{c}^{\mathrm{l}}$ ients receiving MCH/FP services from the program since the adoption of the integrated approach to service delivery. There has also been an increase in the CYPs for all the methods including condoms.

- $\quad$ Although practitioners felt that client waiting times have increased, clients said that they still find these times acceptable.

- The project staff have a better image in the community as they are no longer viewed as people only interested in stopping women from giving birth.

- Many clients with asymptomatic STDs are identified and treated as a result of usin integrated approach 
The study has shown that despite the teething problem FLEP is experiencing, adding STD and HIV/AIDS services to an MCH/FP program, service providers and clients. This is contrary to the fears that since STD and HIV/AIDS are stigmatized conditions, therefore, adding their management to the well established and accepted MCH/FP programes will have negative effects on the latter. 


\section{Background}

Busoga Diocese of the Anglican Church of Uganda covers three districts including the city of Jinja, Kamuli and Iganga in eastern Uganda. There are approximately 1,900,000 million people of one ethnic group living within the Diocese. The majority (90\%) live in rural area and $22 \%$ are women in the reproductive age group. The Diocese is divided into subparishes whose boundaries coincide with the government administrative boundaries for similar divisions. Each of these sub-parishes has approximately 11,000 people. The CPR reported for the study area of $19 \%$ is much higher compared with the National average of $8 \%$. The DUS data is presented at Provincial rather than District level and as such it is not possible to know the average for the whole Diocese.

The Diocese with assistance from the Evangelische Zeutralstelle fur Eutwickliahelfe (EZE) in Germany started a Multi-Sectoral Rural Development Project (MSRDP) in 1976 V) facilitate effective participation of women in rural development programs. The project covers 49 sub-parishes with an estimated population of 540,000 people. The sub-parishes were selected using a criterion that allowed for representation of the whole Diocese. Women were helped to participate in income generating activities, other activities that would enhance childrens' nutritional status, control of childhood diarrhoea diseases and start water projects. Through this program, the diocese operates 46 small clinics and health posts that provide basic curative services in the rural areas and two additional clinics in urban centers (Kamuli and Jinja). There is a development committee for each area with fifteen members selected by the community whatever their religious affiliations The development committees are divided into subcommittees one of which is the health subcommittee. The health subcommittee is responsible to all the project clinics and other health services in project area. The health subcommittees are responsible for hiring the clinic staff, identification of the VHWs, mobilization of resources to pay the clinic staff, purchase of drugs and construction of the physical facilities. Through these health subcommittees, the rural communities participate in the planning, resource mobilization and management of their health services.

During the implementation of the NISRL)P it was observed that womens' participation in these development activities was limited due to time constraints. Maternal and under-five morbidity and mortality were high. Women were, pending large amounts of time taking care of children and their other culturally defined roles leaving little time for them to participate in any meaningful development activities. Through the MSRDP the Diocese staff also realized that women did not have access U) antenatal care, family planning and child welfare services. In 1983, with assistance from World Learning Inc. (formerly known as Experiment in International Living Project) the Diocese started looking for funds to respond to these identified needs. Two projects, one on family planning services and the other on child survival were developed and funded through the Pathfinder Fund and CARE International, respectively. The family planning project was later called the Family Life Education Project (FLEP).

1 Shumba S.S., (1995) Family Life Education Project (FLEP): End of Project Evaluation Report. Pathfinder International (NCAIUGA:001-3) 


\section{The Family Life Education Project}

The Family Life Education Project started operating in 1986 with the main objective of increasing womens' access to PP services. This was to be achieved by introducing UP services in the diocese using the existing MSRDP clinic facilities and through recruiting and training voluntary Village Health Workers (VHW). The VHWs were expected to raise awareness about MCHIFP services and motivate clients to utilize these services now that they were available at the clinics. All staff providing services in the project clinics were trained in the provision of FP, child welfare (CWF) and diarrhoea control services. The health subcommittee members were also trained in management, basic accounting, income generation and community mobilization skills. Although the project started with ten clinics, it expanded to include all the 48 MSRDP clinics within the first four years. Besides training staff, the project provided basic equipment and supplies required in the provision of UP services. At the time the main activities of the project were to promote PP services and make them available to the clients.

The project has five departments: service delivery, finance, administration, communication/training, and community development/mobilization. The heads of these departments with the project manager form the project management team. The management team is responsible for planning, resource mobilization and monitoring of all project activities. They are answerable to the project director who currently is the Bishop of Busoga Diocese.

The project area is divided into eight zones headed by zonal supervisors who have a medical background and have worked in the project as practitioners ${ }^{2}$. Zonal supervisors are responsible for supervising the clinic activities, organizing zonal training for the staff within their zones, acting as liaison officers between the field staff and the head office and also provide technical assistance to field staff.

\section{Clinic services}

All 48 clinics provide family planning, STI and/or HIVIAIDS counselling and other basic curative services daily. In 1994, a total of 26,429 (52\% new and 48\% revisit) client visited the clinics for family planning services. Most of the new family planning clients served at the clinics accepted to use Depo-Provera (38\%). The pill, condom, and IUD were accepted by $16 \%, 16 \%$ and $13 \%$, respectively. Tubal ligation and vasectomy were provided to $10 \%$ and $0.01 \%$ of the new clients, respectively. The rest of the clients accepted to use jelly (3\%) and foaming tablets (2\%). During the same period, the clinics provided STD treatment to 2,160 clients.

Only 15 of the 48 clinics provide antenatal care and delivery services while child welfare is available at 33 of the clinics. Even at the clinics providing ANC and CWF, these services are available only once and twice a week, respectively. Data on MCH services was available for the period July - December 1994 only. This is because prior to this period, FLEP was not responsible for the management of MCII services and as such data were not easily

2 The clinic-based service providers in the Farnily Life Education project are called 'Practitioners". 
available to the project. During that period, the clinics provided MCII services to 29,235 clients. Clients seeking ANC from these clinics accounted for $23 \%$ of the MCH clients. The clinics conducted 1079 deliveries and treated 79 women with incomplete abortion. The clinics report data for CWF services by type of vaccinations given making it difficult to establish the total number of children served at these clinics.

\section{Community-based services}

The project uses a community-based approach to reach out to clients through home visits, public rallies and youth outreach programs. The community based approach involves motivation and counselling for family planning services and distribution of the non clinicbased family planning methods by 162 trained VUWs ${ }^{3}$. The VHWs also counsel and motivate clients for antenatal, postnatal, child welfare, STD and HIVIAIDS services. Each VUW has been assigned a defined geographical area within which they are expected to carry out their activities. They prepare their own schedule of activities which they discuss and agree upon with the supervisors weekly. In 1994 the VHWs provided family planning services to 28,267 (47\% new and $53 \%$ revisit) clients. Over the same period, the VHWs reached 123,229 clients through 40,777 home visits. The VHWs are encouraged to attend and participate in public rallies organized by the administration, the church and other organizations in order to reach the wider community with their messages on reproductive health issues. The VHWs are expected to take advantage of other social events like market days, weddings and funerals to talk to the community about reproductive health. During 1994 , they organized 2,831 public meetings attended by 88,238 participants.

The project has trained 30 community professionals including teachers, community leaders, church leaders and private nurse practitioners who are responsible for the youth program The youth program uses two strategies to reach the youth. One strategy involves teaching inschool youth about reproductive health issues including STDs, HIV/AIDS and family planning using the trained teachers. The second strategy involves mobilizing out-of-school youth into groups which are taught by the community leaders, church leaders and private nurse-midwives about reproductive health. These groups meet at regular intervals when one reproductive health topic is discussed. The project does not have its own curriculum for training the youth in reproductive health but uses one developed by the Ministries of Health and Education. Through these approaches, the program reached 1,756 adolescents, 188 parents and 166 teachers with messages on reproductive health in 1994.

A special team comprising of 20 VHWs has been trained in the development of locally relevant and culturally sensitive IEC messages that they can pass over to the community through drama and songs. This team called "communication agents" visits various project areas and reaches out to the communities with messages on family planning, STD and HIV/AIDS through their songs and drama. The group reaches out to the community through performances at market places, weddings, funerals and at public gatherings organized by the local administration. They have also recorded these songs and plays and are available for sale. In 1994 this group produced four radio spots/talks and two television programs.

Non clinic-based family planning methods are those methods that can be provided without requiring die client to visit a clinic. The methods include condoms, spermicides and the first cycle of oral contraceptive pills. 


\section{Integrating STI, HIV/AIDS and MCH/FP services}

\section{Reason for integrating STI, HIV/AIDS and MCH/FP services}

At the time FLEP was initiated, the effects of the HIV/AIDS epidemic had not been felt within the project area. With time the epidemic started taking a major toll on the population and the resources in the project area. There were many persons both young and old who were dying or suffering from the complications of HIV/AIDS. The community could not understand why FLEP continued to emphasize FP services only when so many people were dying from HIV/AIDS. The community was preoccupied with dealing with the implications of the HIV/AIDS epidemic and FP was no longer a priority to them. Having identified this as an obstacle to the success of FLEP, staff decided to include STI and HIV/AIDS counselling as a service provided to clients receiving $\mathrm{MCH} / \mathrm{FP}$ services from the project clinics, VHWs and through other outreach activities.

\section{Activities undertaken by FLEP to help the integration process}

Training of project staff In 1989, the practitioners were trained and started providing information on HIV/AIDS to clients receiving other services from the clinics. However, the project could not provide all the required training in HIV/AIDS counselling and did not have facilities to test for HIV sero-status. To overcome these obstacles, FLEP started networking with other NGOs that had these capabilities. In 1992, The AIDS support Organization (TASO) and the AIDS Information Center (AlC) were approached to help with training in AIDS counselling and HIV testing. TASO trained all the 162 VHWs and 48 practitioners in HIV/AIDS counselling. In addition, all the practitioners attended in-house seminars on counselling and management of their STIs. The curriculum used for these inhouse seminars covered the modes of transmission, symptoms and signs of the common STIs.

Development and acquisition of appropriate IEC materials and activities: The project has a limited range of JEC materials on family planning and HIV/AIDS including posters, hip charts and films. The IEC materials have been supplied by the Ministry of health (MOH), the Family Planning Association of Uganda (FPAU), the National AIDS Control Program (NACP) and other donors. Besides these sources, FLEP has used the "communication agents" in the IEC teams to develop plays and songs with combined messages on STDs, HIV/AIDS and FP that the community can identify with.

Development of checklists for risk assessment of clients: The project developed a checklist to be used by clinic staff in determining the clients risk status for STDs and/or HIV/AIDS. The checklist asks about marital status, health status of children and presence of symptoms and/or signs suggesting STDs and/or HIV/AIDS. However, the checklist does not include some of the more pertinent and important risk factors like clients' sexual behavior, partners' sexual behaviour and STD history. At the time of this case study no similar checklist existed for the VHWs. 
Laboratory facilities: None of the project clinics have laboratory facilities on site. For HIV testing, an arrangement was made with AIC to establish mobile satellite testing centers within the project area. Clients requiring laboratory tests for other STDs (for example, syphilis) are referred to government clinics and hospitals in the project area. The clients have to travel to the testing centers as the project has no facilities to collect and transport laboratory specimens. In Jinja Municipality, FLEP has made arrangements with some private laboratories to test clients referred by the project at subsidized rates.

\section{The Family Life Education Project Integration Model}

The FLEP management team was asked to list the activities that they expected the project staff to perform that would be considered as part of the initiative to provide STD, HIV/AIDS and $\mathrm{MCH} / \mathrm{FP}$ services using the integrated approach. The list was then used to construct the model described in this case study.

\footnotetext{
The Family Life Education Project's Integration Model

1. Carry out STD/HIV risk assessment for clients receiving MCH/FP services from the MSRDP clinics;

2. Screen clients receiving MCH/FP services for STDs and HIV/AIDS using a diagnostic checklist;

3. Identify and refer clients requiring HIV testing;

4. Diagnose and treat clients with STDs using the syndromic approach;

5. Inform and educate all clients receiving family planning and other services from the MSRDP clinics and Village Health Workers about STDs and HIV/AIDS;

6. Inform and educate persons living within the project areas about STD and HIV/AIDS through public meetings, seminars, drama and song;

7. Inform and educate both the in-school and out of school youth about STDs and HIV/AIDS using trained school teachers, community leaders, church leaders and private nurse midwives.

8. Raise awareness and create support for the integrated reproductive health services among the health sub-committees and other community leaders.
} 


\section{Study Methodology}

The Population Council's Africa OR/TA Project II, in collaboration with other consortium members (Pathfinder International, REDSO/ESA, Africa Bureau, Data for Decision Making Project at Harvard and CDC in Atlanta) developed a methodology for conducting case studies of programs and projects that have adapted the integrated approach to provide STI, HIV, AIDS and MCH/FP services. The methodology embraces four activities:

Review of available data and reports, in-depth interviews with management team, a modified Situation Analysis and guided group discussions. This methodology was used to carry out the case study of FLEP in December 1995.

Review of available data and reports: The DHS reports, Ministry of Health Annual Reports, Census reports, FLEP quarterly reports and strategic plans were reviewed. The review was used to establish the characteristics of the catchment area contraceptive practices and service statistics for STIs, HIV and AIDS. The review was also used to trace the evolution of the project activities to the time of the case study and to identify future strategies.

In-depth interview with program management team: The management team of FLEP including the manager and heads of the various departments were interviewed using a semistructured interview guide. The interview guide covered their understanding of the integration process, historical evolution of the integration process (why, how and when did the process start), the type of integration model and its components, activities carried out to help the process, resource mobilization and budgeting, monitoring and evaluation activities, policy commitment and experiences to date.

Modified Situation Analysis: The modification involved an expansion of the existing data collection instruments to include questions on staff and client knowledge of STIs, HIV and AIDS, staff use of management procedures (risk assessment, screening, diagnosis, treatment, counselling, IEC and referral) and the actual and potential mechanisms for integration of STI and/or HIV/AIDS services with MCH-FP services. The data collection instruments were revised using a list of indicators and questions recommended by $\mathrm{WHO}^{4}$, the STD Subcommittee on Reproductive Health Indicators ${ }^{5}$ and the checklist developed by FLEP . $^{6}$ Data were collected on the status of clinic facilities, management information systems, personnel, client experiences at the clinics, the non clinic-based service delivery systems, and service statistics, staff, interactions between clients and staff and exit interviews with FP and $\mathrm{MCH}$ clients using the modified instruments.

4 Mertens T.Carel M., Sato P., et al, (1994), " Prevention indicators for evaluating National AIDS Control Programs." AIDS, 8:1359-1369

5 Dallabetta G., and Hassig S., Eds in Indicators for Reproductive Health Program Evaluation, (1995). A final report of the Subcornrnittee on STD/HIV. A publication of Carolina Population Center, Chapel Hill, NC 27516-3997 
Seventeen of the 49 clinics were selected for the study. These 17 clinics were within the sub-parishes that participated in a catchment area survey carried out by Pathfinder International soon after this case study. Information on accessibility, publicity, physical infrastructure, supplies, equipment, commodities and service statistics was obtained for the 17 clinics using the clinic inventory questionnaire. Twenty-one practitioners found providing services at the 17 clinics and 45 VHWs were interviewed.

A total of 117 women who received MCH-FP services at the 17 clinics were interviewed about their interactions with the clinic staff; 79 had attended for MCH services while 38 attended for family planning services. Interactions between clients and service providers were observed for $20 \mathrm{FP}$ and 45 MCR clients. Sixteen of the FP clients were new users. Of the $\mathrm{MCH}$ clients observed, 23 received child welfare services only, 14 received antenatal care only, and eight received both services.

Guided group discussions: Guided group discussions were held at three of the health facilities visited during the study. The practitioners, supervisors, VHWs and members of the health subcommittees at these health facilities participated in these discussions. Using a checklist the investigator and interviewers led and guided the discussions. The checklist covered a wide range of topics including participants' attitudes and practices towards the provision of STD/HIV services together with MCH/FP services, job satisfaction, impact of using the integrated services on utilization of other clinic services, cost and sustainability of the program. 


\section{Principal findings from case study}

\section{Preparedness or basic infrastructure to provide MCH/FP, STI and HIVIAIDS services}

Clinic Facilities: Many clinics operate in semi-permanent structures where areas for procedures like waiting, counselling, and examinations are separated by materials that do not provide auditory privacy. Through FLEP, communities are being helped to construct more permanent structures designed to facilitate the provision of good quality services to clients. Through this assistance, 25 sub-parishes have already completed constructing permanent structures for their health facilities while the rest are at various stages of construction. Most of the facilities are in the rural areas where there is no electricity and/or piped water. Due to the way most of the facilities were constructed there is very little natural light that gets into the examination rooms and staff rely on torches to provide light for pelvic and other examinations.

Equipment and supplies: Not all of the facilities are adequately supplied with equipment for use in providing FP services (Figure 1).The 10 facilities with sterilizing facilities were using charcoal stoves and nonpressurized instrument containers to sterilize the equipment by boiling. This requires that the instruments are kept at the boiling point for a minimum of 20 minutes a condition that is difficult to achieve with charcoal stoves. Although 14 of the clinics visited were providing child welfare services, four of them did not have a functioning child weighing scale. One of the clinics not providing CWF was had a child weighing scale.
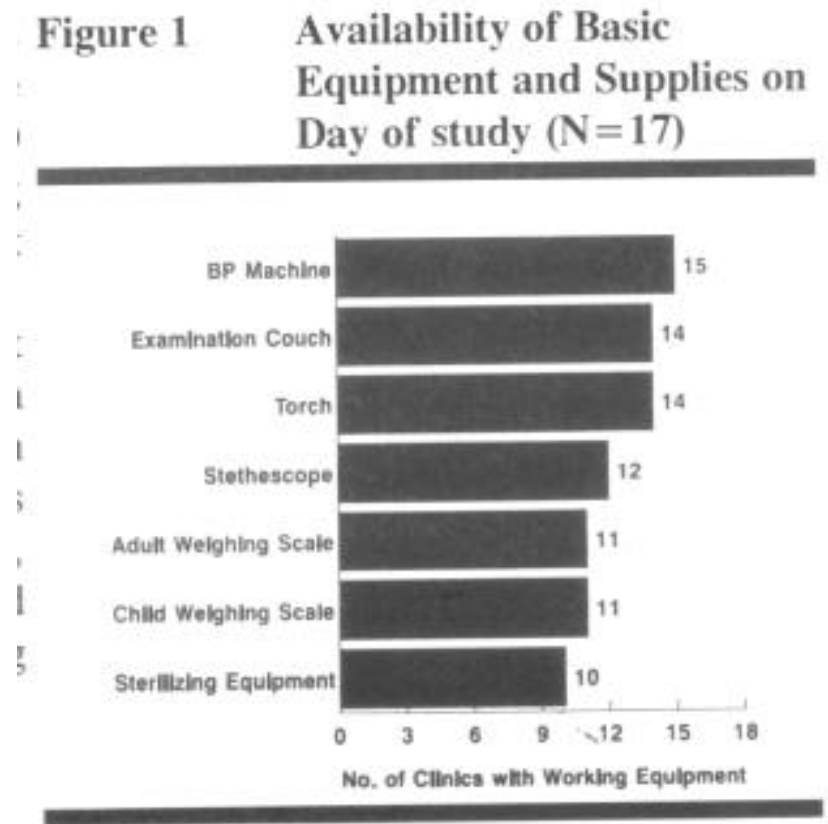
According to the project manager, each clinic has been supplied with one IUD insertion kit. This kit includes a vaginal speculum, tenaculum, uterine sound, and sponge holding forceps and artery forceps. Fifteen of the 17 clinics visited had at least one of each of these instruments (Figure 2). Due to the limited resources, needles and syringes are often reused at these facilities especially for immunization and other curative services. Reusing equipment and supplies calls for very efficient sterilization facilities, which are lacking at most of the facilities. Waste disposal is an important component of infection prevention. None of the clinics visited had a sluice room for handling contaminated instruments/ materials and only two had acceptable sharp's disposal facilities. Only six of the clinics had dustbins and waste disposal pits for handling their waste materials while none had access to incineration facilities.

Most of the facilities are barely managing to provide the basic MCH/FP service given the inadequate infrastructure and limited supplies of equipment and other materials required to provide these services. The addition of STI and/or HIV/AIDS services has increased the demand on the limited equipment and supplies available and may compromise the quality of services provided.

IEC Materials: IEC materials on STDs and/or HIV/AIDS are very few and the project was last supplied with these in 1991/1992 (Figure 3) Posters with dual messages on FP and STI and/or HIV/AIDS were found at only three clinics. The program manager said that the available IEC materials have not been very useful in the communities served by FLEP since most of the posters, pamphlets and films are in English and have been developed in urban environments within cultures that are foreign to their clients. Therefore, the project relies more on the songs and drama developed by the communication agents to inform, educate and counsel clients.
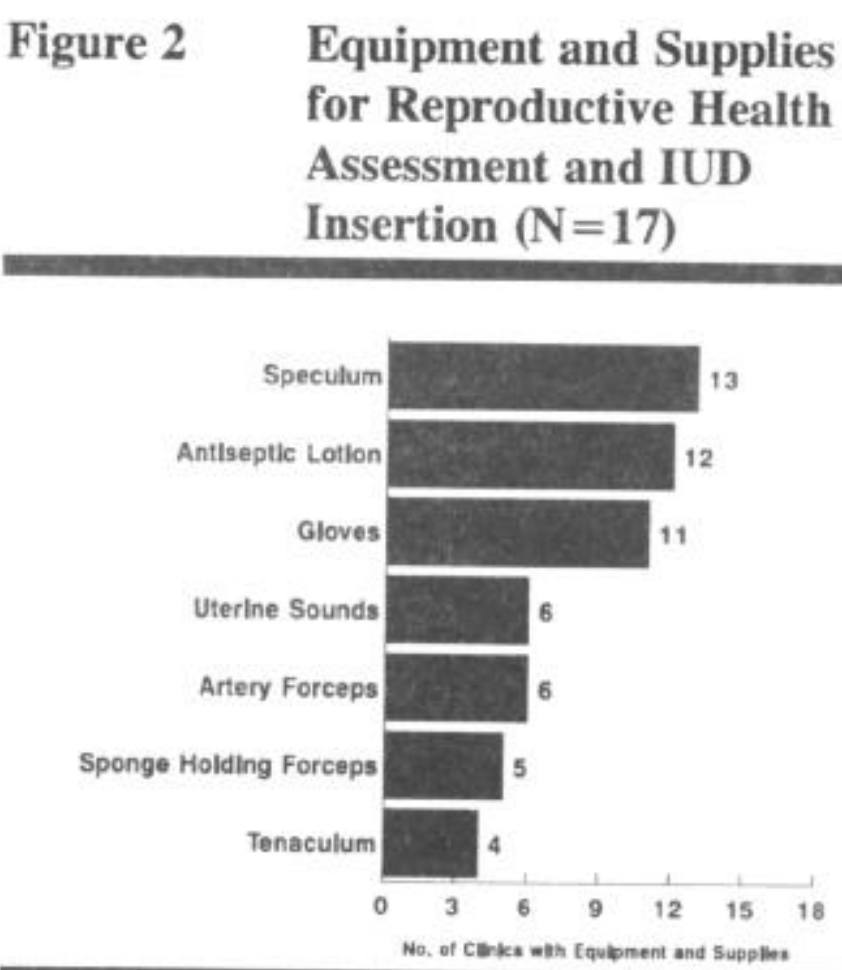
Although all clinics are expected to hold group health-talks for their clients, these were observed at only 10 of the clinics visited during this study. These data show that wherever staff gives the group healthtalks, they include FP, STDs and HIV/AIDS. Service providers said that it is difficult for them to organize group health talks daily because clients do not come to the clinics at the same time and in many cases there are only one or two FP clients at the clinic for several hours. They therefore, felt that waiting for enough clients in order to give a group health talk would greatly increase the waiting time for the clients. It was observed that most MCH/FP units at the clinics are not busy most of the day except where there were scheduled services like antenatal care and child welfare.

\section{Figure 4 Topics Covered During Health Talks Observed $(\mathrm{N}=\mathbf{1 0})$}

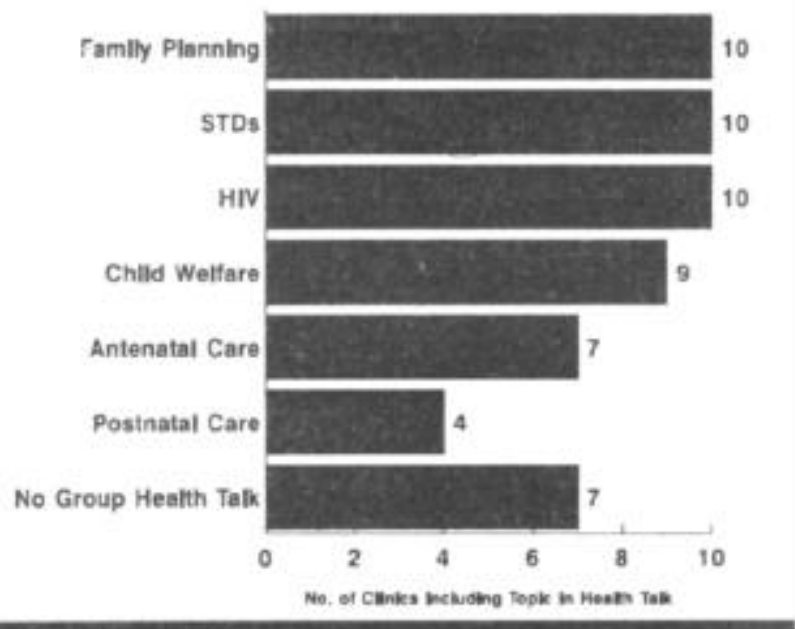

\section{Accessibility of services}

Opening times for clinics: All clinics are expected to start providing service at 8.00 A.M. The study found that the majority (11) of the clinics visited started providing services to clients at the expected official time. Most of the women interviewed during this case study were satisfied with the times that the clinics were open.

Availability of services: Findings from this study Figure 5 show that STD and HIV/AIDS services are available at most of the clinics daily (Figure 5). Only three of the clinics visited were not providing HIV/AIDS counselling on the day of the study while counselling and treatment for STDs were not available at one clinic Child welfare, antenatal care and postnatal care were available at 14,10 and three clinics respectively. These data show that some project clinics are not yet providing STD, HIV/AIDS, $\mathrm{MCH}$ and FP services on a daily basis.
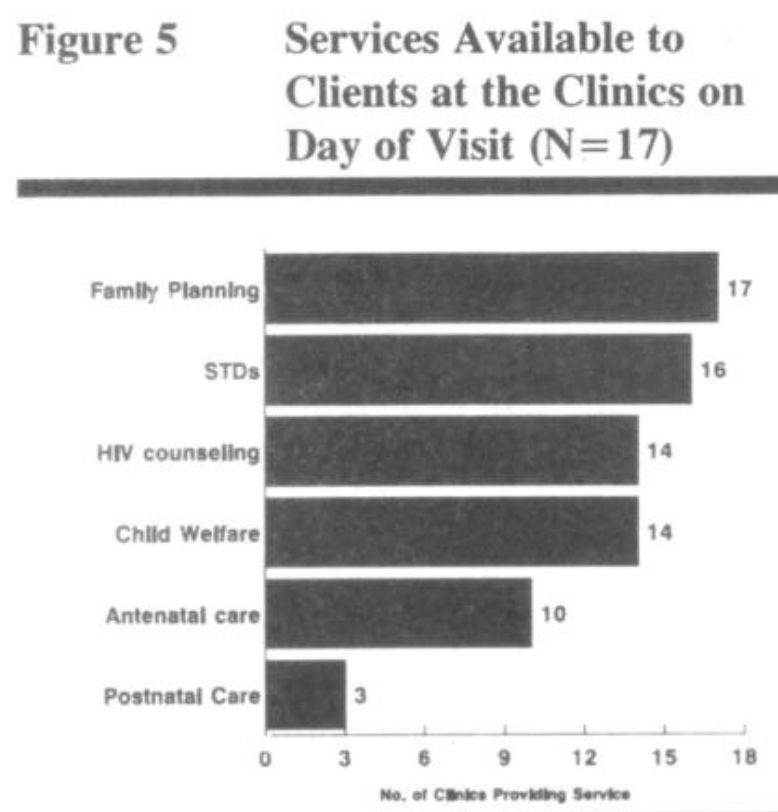
Availability of signs announcing services: Data in Figure 6 show that most clinics (15) had a sign announcing the availability of family planning services. All the clinics with a sign were using the Ministry of Health logo for the family planning program. The project manager said that she has noticed an increase in the number of clients seeking family planning services since the introduction of the national logo. However, fewer than one-third of the clinics visited had any signs informing clients about the availability of STD, HIV/AIDS, child welfare and antenatal care services. The health sub-committees are responsible for making available funds to prepare the billboards. Given the scarce resources available to these committees amid the many demands they have to respond to, signs

Figure 6 Signs Announcing Services Available at the Clinics

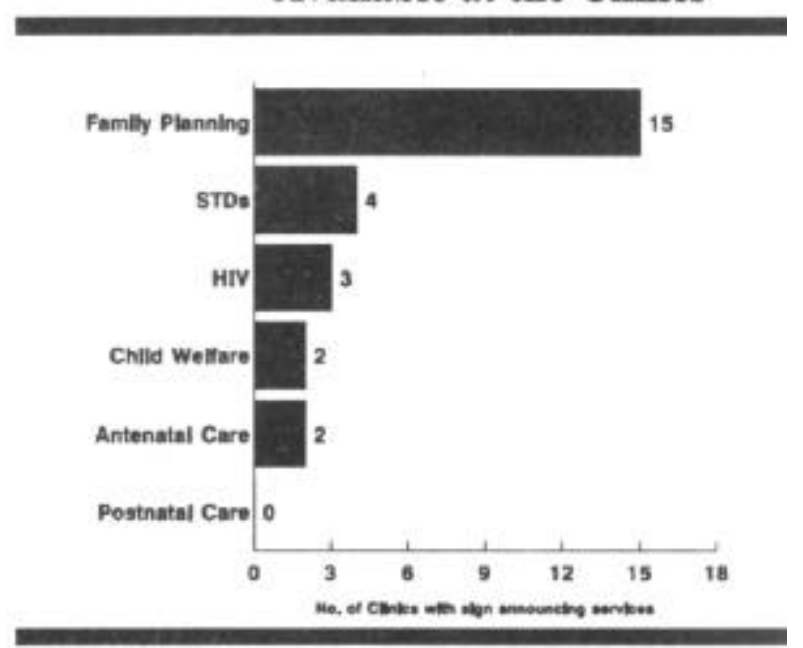
announcing services may not be a priority to them. However, the successful introduction of the FP logo and the increase in clients observed should be used to encourage the health sub-committees of the need to advertise the other services available at the clinics.

\section{Service provider preparedness to provide MCH/FP and STI and/or HIV/AIDS services}

\section{a) Clinic-based staff (Practitioners)}

Availability of staff There is one practitioner per project clinic assisted by the zonal supervisors whenever there is a need. The practitioners are medical assistants, registered and/or enrolled nurse midwives. Many of these practitioners are on secondment from the $\mathrm{MOH}$ while the rest are employed by the health sub-committees. The practitioners are responsible for providing FP, ANC, CWF, STI and/or HIV/AIDS, and other curative services. They are also responsible for supervising the VHWs working within the catchment areas for the clinics.

Staff training and experience: Over two-thirds of the practitioners interviewed said that they provide family planning, STD counselling or diagnosis and treatment, HIV/AIDS counselling and child welfare. Fewer than half said that they provided ANC and PNC, which is not surprising, given that only 15 of the 48 clinics provide these services. The practitioners who said that they provided family planning, STD and HIV/AIDS services had provided the service for five, three and two years, respectively, on average before the case study. These data show that practitioners at the clinics have a short experience in providing STD and HIV/AIDS services compared with family planning and other $\mathrm{MCH}$ services. 
Most of the practitioners completed their basic training more than 10 years before this study (Mean 18, Range 5-33 years). Although more than half the practitioners interviewed had covered antenatal care, child welfare, family planning and STD services in their basic training, only two said that HIV/AIDS was covered (Figure 7). Most of the practitioners who have attended a refresher course in family planning, STD and HIV/AIDS have done so in the two years preceding this study.

The practitioners were also asked whether they felt that the training they had received was adequate. Nearly all (20) said that the training in family planning was adequate while only 12 said that the training was adequate for CWF, STD and HIV/AIDS services. Fewer than half said that the training in ANC was adequate. The lack of emphasis on training in ANC, CWF and PNC by FLEP was because these services did not fall directly under the project until 1995.

The 19 practitioners who said that they had attended a course on STD and/or HIV/AIDS were asked to name the topics covered during the training they attended (Figure 8). Risk assessment and screening of clients for STD and HIV/AIDS are major components of the integration model adapted by FLEP yet many practitioners had not been trained in these subjects. This because the training curriculum used by FLEP to train its staff at the beginning of the project did not include these topics.

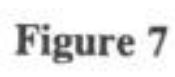

Training Background for the Practitioners $(\mathrm{N}=21)$

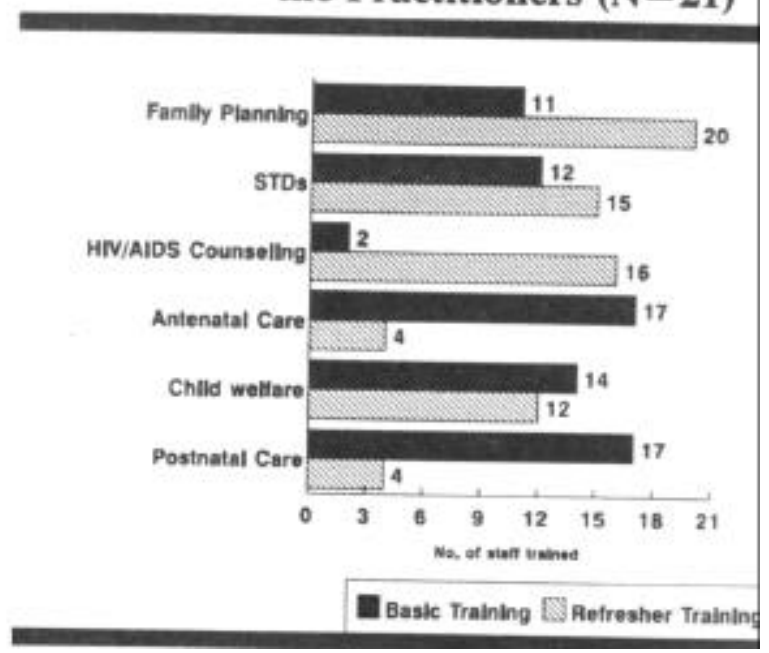

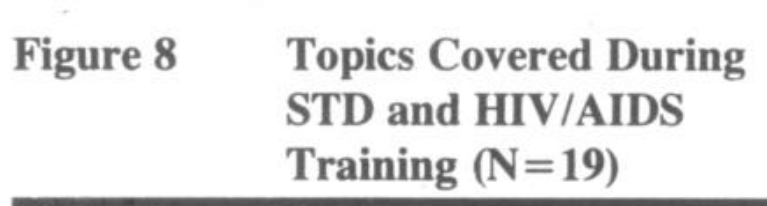

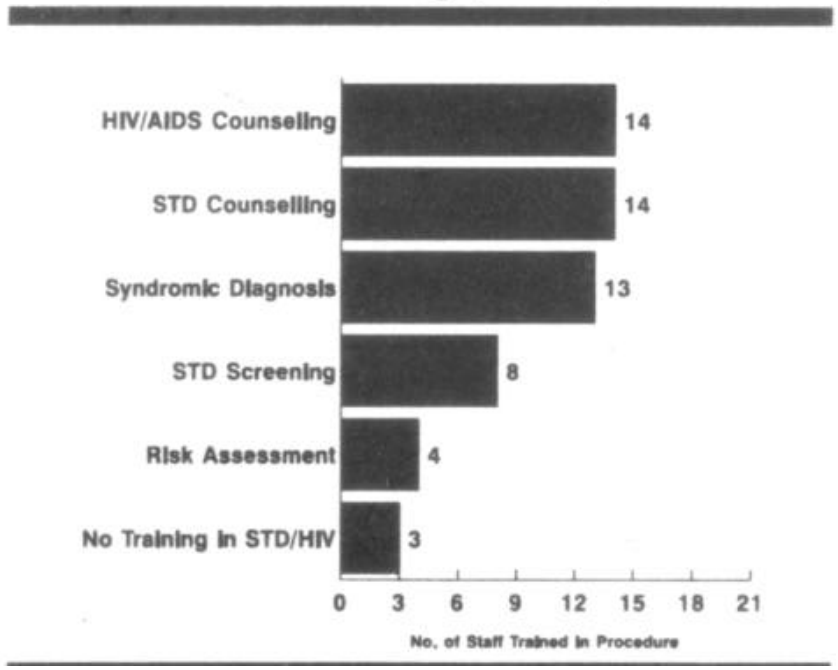

b) Village health workers

Availability: At the time of the case study there were 162 VHWs. The VHWs are volunteers nominated by the community through the health subcommittees of each sub-parish. The project gives the VHWs bicycles, transport allowance, bags, uniforms and cupboards to facilitate their work. During the case study, 45 of the 162 village health workers were interviewed. The VHWs interviewed had worked with the project on average for five years (range 1-9 years). 
All 117 clients interviewed at the clinics were asked whether they knew of a VHW within their home area. Seventy six percent of family planning and $63 \%$ of MCII clients interviewed said that they knew of a VHW in their sub-parish. Although most of the family planning clients $(68 \%)$ said that a VHW had visited their home, fewer than one-third of the $\mathrm{MCH}$ clients said so. Most of the clients whom a VHW had visited were visited within the three months preceding this case study. Project clinics provide services to clients living outside the project areas. It is therefore possible that those women who said that they were not aware of a VHW working in their home area and those who said that they had not been visited at home live in sub-parishes that are outside the project area.

Training and experience: The project trains the selected VHWs in FP motivation, counselling and distribution of non-prescription family planning methods including pills. Besides family planning, they have been trained on how to motivate and counsel for ANC, CWF and STD/HIV services. All the VHWs interviewed had attended a basic course in motivation and counselling for family planning services. The majority (78\%) had also been trained in the techniques used for counselling on STDs while $42 \%$ said that they had been trained in counselling for HIV/AIDS.

The VHWs are expected to educate and provide counselling on STDs and RIVIAIDS to the communities they serve. Besides, education and counselling, they are expected to motivate and refer clients to the clinics for STD and HIVIAIDS services. This can only be achieved through identification of clients at risk and in need of these services. They are also expected to follow up clients who have been diagnosed to have STDs and/or HIVIAIDS to reinforce and ensure clients are following the instructions given at the health facility. These responsibilities require that the VHWs have the knowledge and skills to undertake risk assessment, educate and counsel clients about STDs and HIV/AIDS.

All VHWs interviewed were asked if Figure 9 they knew of any disease transmitted through sexual intercourse and all said yes. They were then asked to list the symptoms and signs associated with such diseases. Figure 9 shows that knowledge of the common symptoms associated with STDs and HIV/AIDS is reasonably high among the VHWs. However more than one-third of the VHWs were nor aware of some common symptoms associated with these diseases like lower abdominal pain and pain on passing urine. This relative lack of knowledge among some of the VHWs may be due to an inability of these VHWs to retain what they have been taught over a long period without refresher or due to poor coverage of these topics during their training.

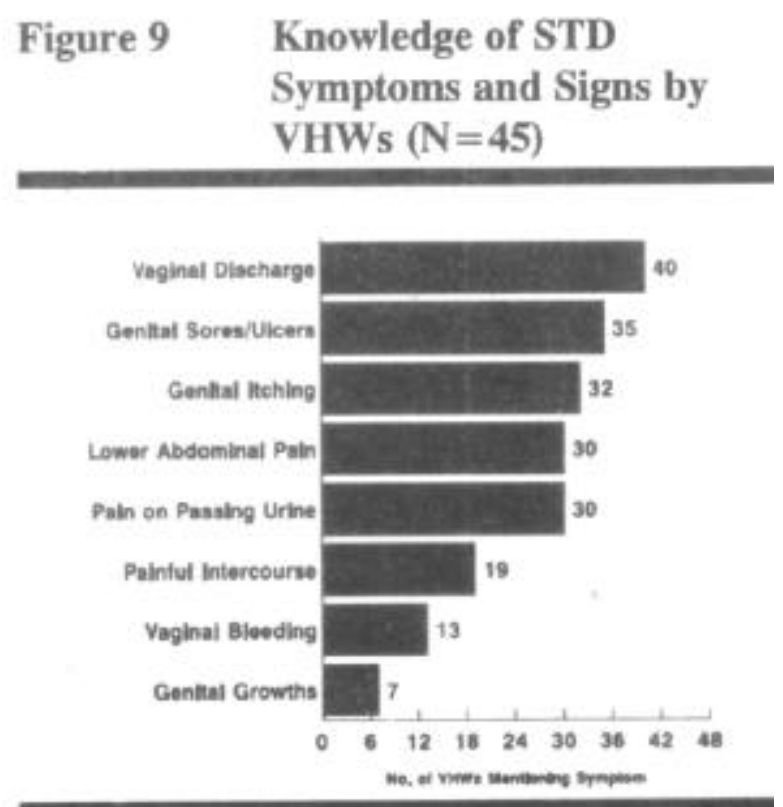


Although most VHWs interviewed had IEC materials on family planning, fewer than one-quarter had any IEC materials on STDs, HIVIAIDS, antenatal and postnatal care and only one-third had materials on HIV/AIDS (Figure 10). In the past, FLEP has relied mostly on songs and drama as the main approach to provide information, education and counseling about STDs, HIV/AIDS and family planning to the community. This is because the project practitioners believe that using wriuen materials in a rural community with low literacy rates may have little effect.

\section{Implementation of the Integration Model}

The FLEPs experience with the integration model is described below using data from staff interviews, observations of the interaction between service providers and clients receiving ANC, CWF and family planning services by trained interviewers and exit interviews for the clients. Seventy-nine clients who had attended the clinic for $\mathrm{MCH}$ services and 38 who attended for family planning services were interviewed. Interactions with service providers were observed ft)r $20 \mathrm{FP}$ and $45 \mathrm{MCH}$ clients.

\section{a) STD and HIV/AIDS risk assessment for clients}

Practitioners were asked what type of clients they routinely asked questions that would help in deciding the risk status for STDs and HIV/AIDS. Findings by the study (I\$igure I suggest that practitioners in the project are more likely to carry out ST[)/1 IV risk assessniei t tor clients seeking family planning servicel than those seeking ANCI or women bringin4 their children for $\mathrm{CWF}$ services. This may be an indication of the difficulues practitioners have in initiating discussions about sexual behavior and STDs with MCH clients. Many clinics do not provide ANC and CWF on a daily basis. The 'scheduled CWF services are offen overcrowded and provided under a tree due to lack of adequate space and the large number of clients turning up for these services. This makes it even more difficult for the practitioners to carry out risk assessment and screening for STD and HIV/AIDS.

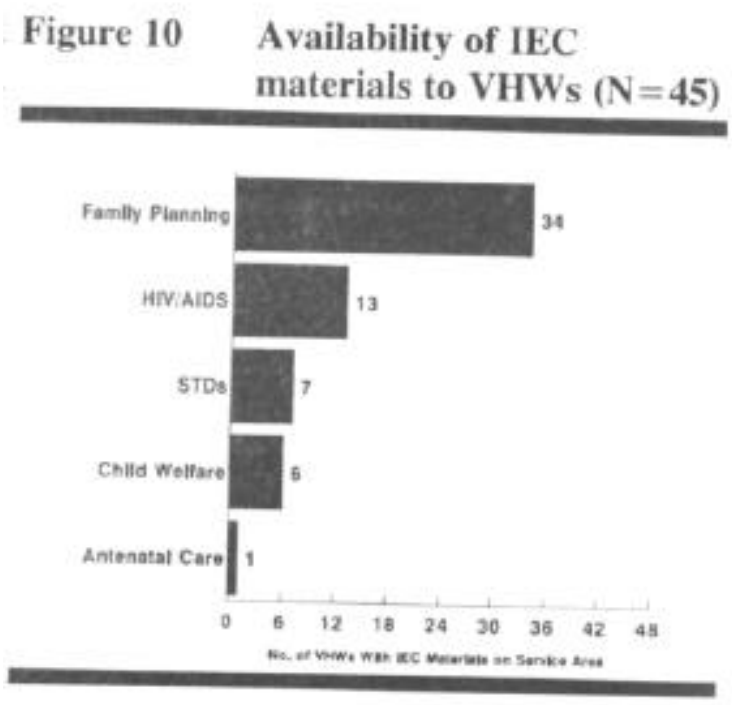

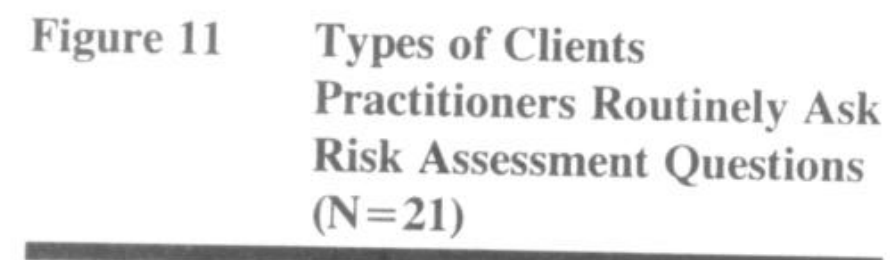

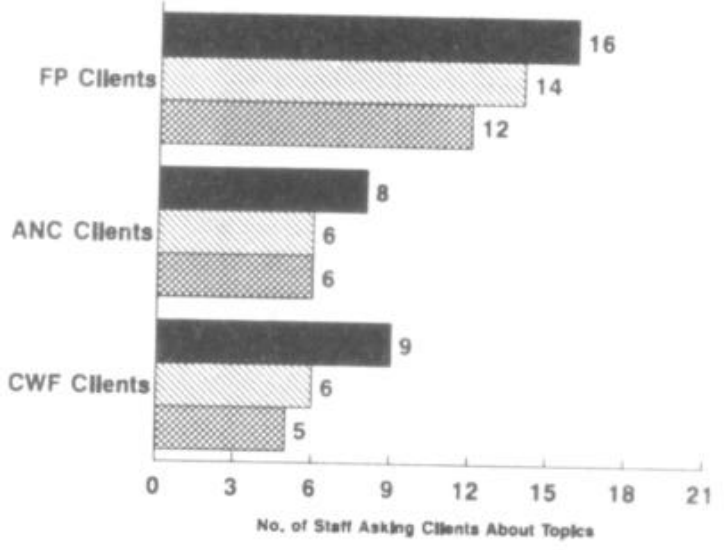

STD Hlstory $\mathbb{Q}$ Sexual behavlor $\approx$ Partners Behavlor 
The VHWs were also asked if they routinely ask clients seeking antenatal, child welfare, and family planning services about history of STDs, clients' and/or partners' sexual behaviour. Data from the study shows that over half the VHWs do not routinely obtain information on these topics from clients seeking ANC and CWF services. This is not surprising given that the VHWs are not expected to screen clients for STDs and also that they have very limited contact with ANC and CWF clients. However, the majority (80\%) said that they asked about STD symptoms for clients seeking family planning services but more than one-third do not routinely ask about clients' and/or partners' sexual behaviour.

Figure 12 shows that all the new family planning clients observed were asked about the number of new sex partners in the past year but fewer than half were asked about other known risk factors for STDs and HIV/AIDS. These data show that few clients are asked about or volunteer information on the risk indicators that would help the service provider in determining their STD and/or HIV risk status.

There are some differences between what the practitioners say they ask about and what was observed during service provision. For example more than half the practitioners said that they routinely ask family planning clients about their sexual behaviour, that of their partners and history of STDs but only one and five clients were observed to be asked about partners' sexual behavior and history, respectively.
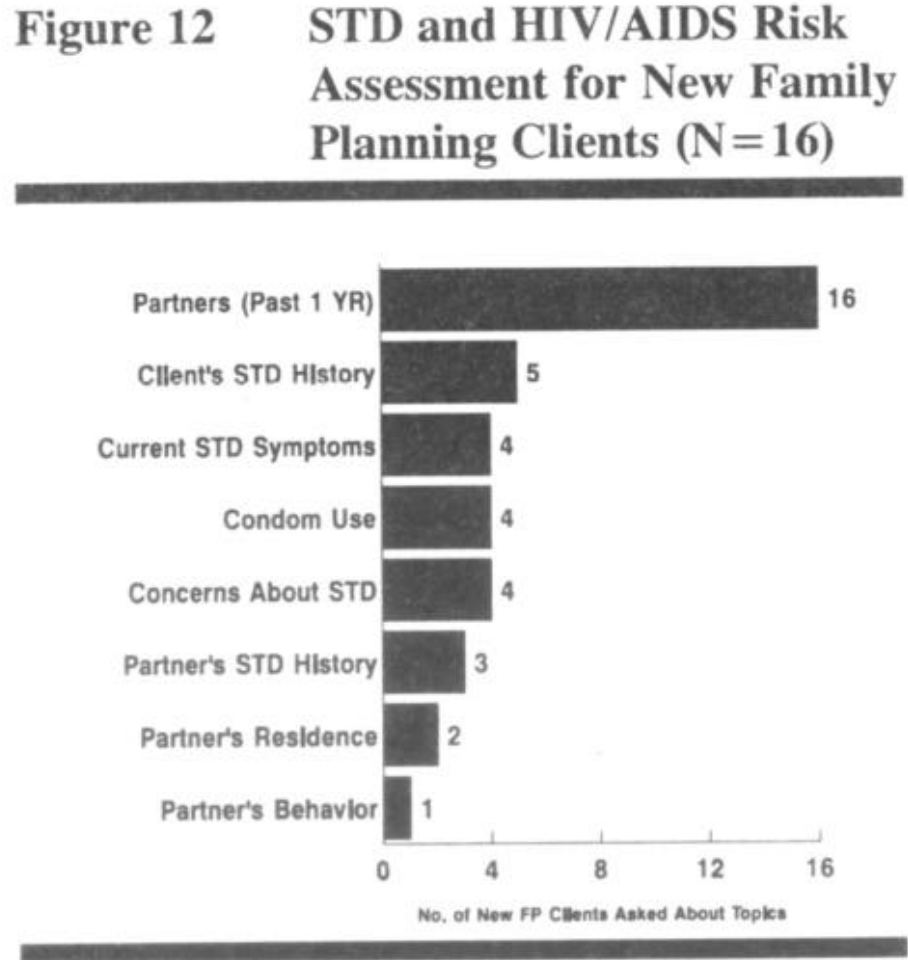


\section{b) Screening clients for STDs and HIVIAIDS}

History taking: Figure 13 shows that the practitioners do not always follow the FLEP diagnostic checklist ${ }^{7}$ when taking history from new family planning clients. For example more than one-third of the new family planning clients observed were not asked about family or medical history, past experiences with STDs and history of lower abdominal pain. The data show that despite the presence of a diagnostic checklist new family planning clients are not adequately screened for STDs.

\section{Figure 13 History Taken to Screen Clients for STDs by Clinic Practitioners $(\mathrm{N}=16)$}

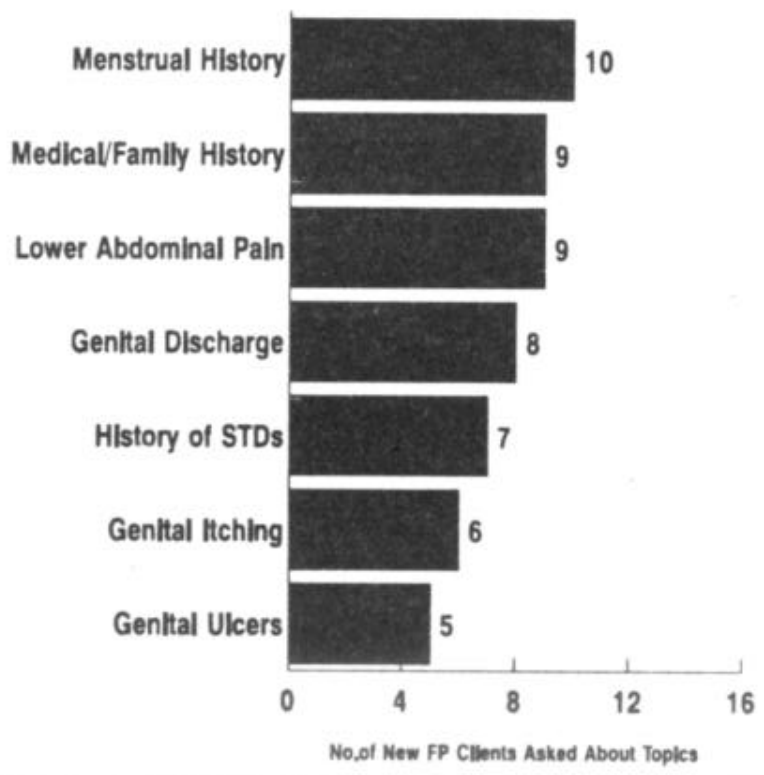

Figure 14 Clinical Assessment Performed for New Family Planning Clients $(\mathrm{N}=16)$ assessing a new family planning client. Figure 14 shows that over half the clients had their weight, blood pressure and a physical examination carried out while only half the clients had a pelvic assessment done. Breast examination is a simple, inexpensive procedure but less than half of the new family planning clients had their breasts checked for abnormalities. These data show that practitioners do not always carry out a complete clinical evaluation of the new family planning clients.

Clinical examination: Practitioners are expected to follow the National Family Planning Policy Guidelines and Service Standards when

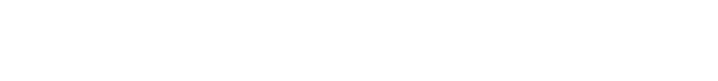

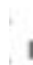

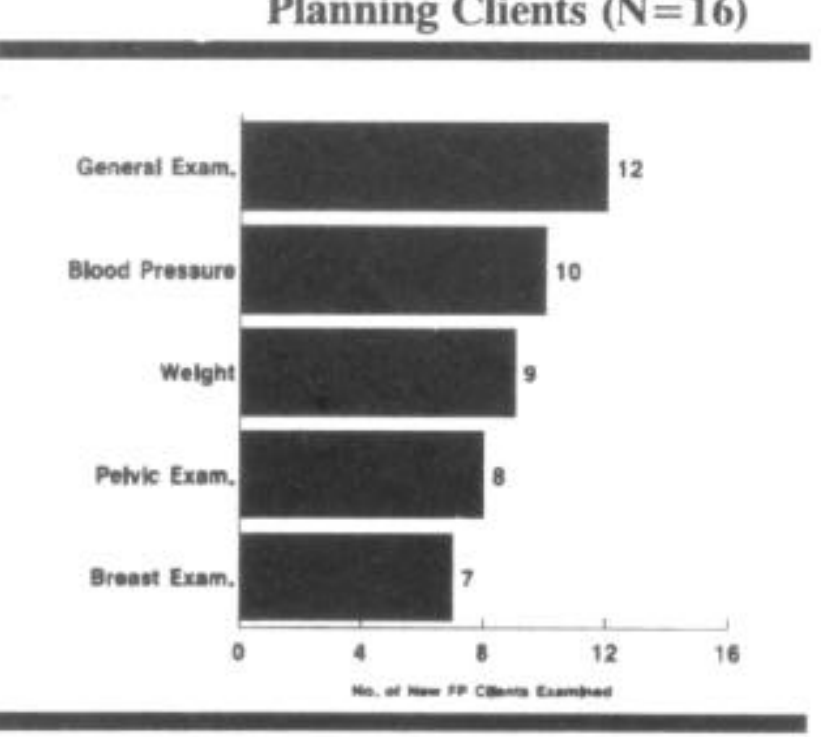

7 See Diagnostic checklist OP. Cit 
Pelvic examination: Eight pelvic examinations were observed. The procedure was explained to seven of the eight clients before it was carried out and practitioners washed their hands and wore sterile gloves before carrying out the procedure for all eight clients. Practitioners visually inspected the external genitalia in the eight procedures. Bimanual palpation was carried out in all the eight procedures and a speculum examination carried out in six procedures. When pelvic examinations are carried out practitioners follow the correct procedures.

Laboratory tests: All clients requiring laboratory tests are referred to the government facilities or to the mobile HIV testing facilities operated by the AIDS Information Center (AIC) in the study area. This arrangement has not worked as was expected the government and AIC facilities have rules and regulations guiding their operations that do not facilitate collaboration with FLEP. For example all clients tested by AIC must have pre- and post- test counselling and blood specimen collection done by their own personnel. The test results can only be given to the clients by AIC practitioners. This approach does not facilitate continuity of care that FLEP would like to provide to its clients being the primary care giver in the area. It is common for clients to be mobilized for testing or to receive their results and the AIC team fails to show up for one reason or the other. The failure to honour their appointments with clients especially when the clients are waiting for their results has led to frustrations in the field for the FLEP field practitioners and their clients.

Service providers are expected to screen and/or refer all antenatal clients seen at the MCH/FP clinics to the government facilities for testing and treatment. Only three percent of the service providers interviewed said that they do this and none of the antenatal clients observed was referred for syphilis testing.

\section{c) Informing clients about STD and HIVIAIDS}

IEG on STD/HIV/AIDS for clients: Counselling is a major step in managing STDs and HIV/AIDS. The Uganda Ministry of Health STD/HIV/AIDS Control Unit has developed Guidelines for assessing, informing and treating clients with $\mathrm{STDs}^{8}$ Figure 15 shows that less than half the practitioners said that they would discuss about the modes of transmission of STD/HIVAIDS, partner notification, condom use and the importance of follow up with clients receiving treatment for STDs. These data suggest that practitioners may not be aware of the recommendations on counselling of STD clients by the $\mathrm{MOH}$.

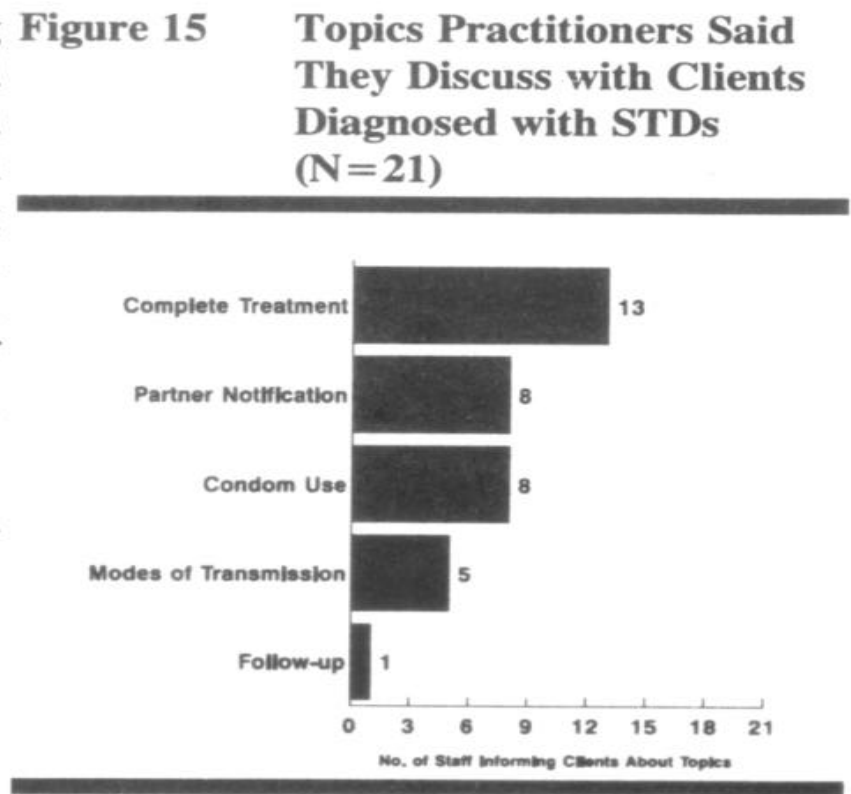

STD/AIDS Control Program (1993). Sexually Transmitted Diseases Treatment Guidelines for Health Care Workers in Uganda. STD/AIDS Control Program, Ministry of Health Entebbe, Uganda. 
Clients were counseled about STIs and HIV/AIDS in $62 \%$ of the 66 consultations observed during the study. Figure 16 shows that ways of protecting oneself from STDs and HIV/AIDS was discussed with more than half the clients who were counselled about STDs and HIV/AIDS. The rest of the topics that practitioners are expected to discuss with clients were mentioned in less than half the consultations. These findings were consistent with what the practitioners reported when interviewed about their.

Most of the new family planning clients were informed about the condom and spermicides as contraceptive methods. However, dual use was discussed with only five clients. Although the numbers are few, these data show that many clients do not get the information that would help them avoid being infected or infecting others with STDs and HIV.
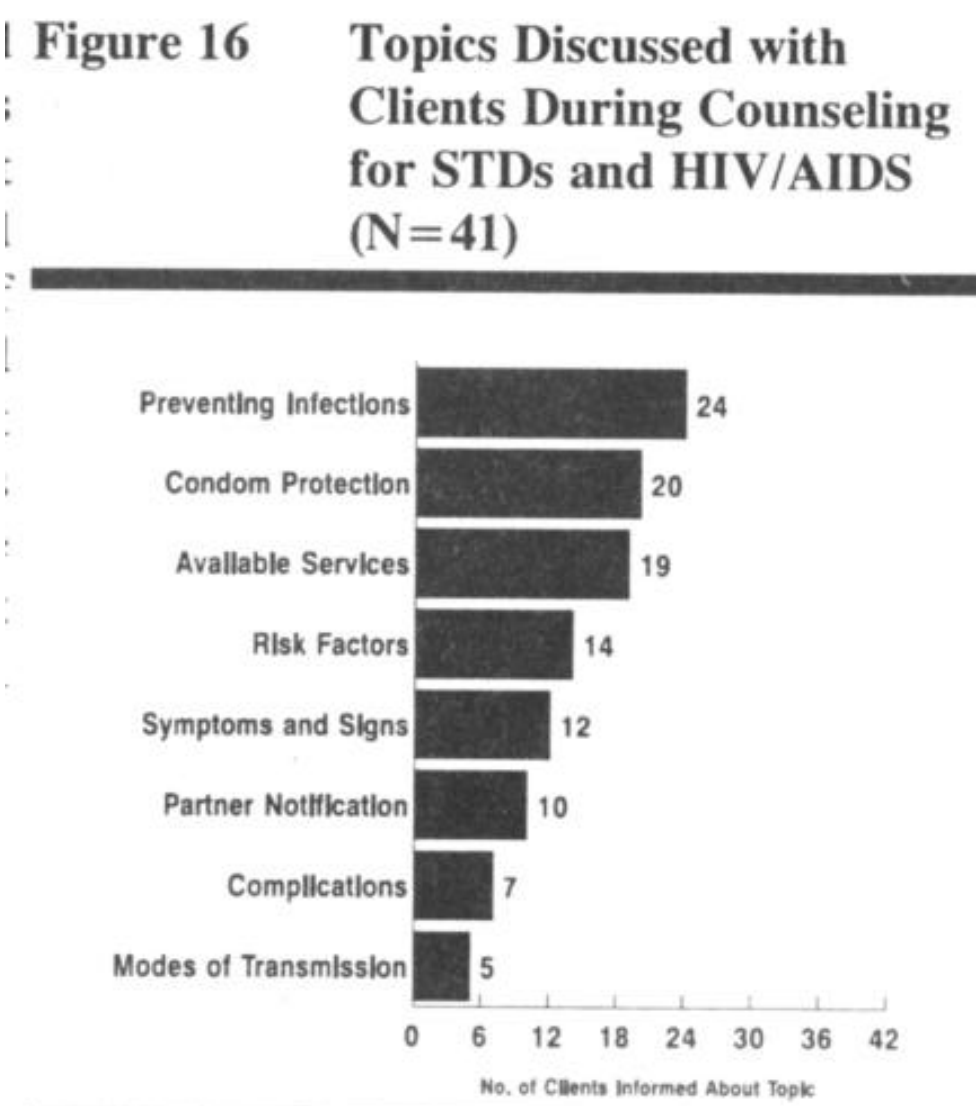

Use of IEC materials/ clients taking home: Flip-charts and contraceptive samples were used when counseling new family planning clients in 11 and 13 of the consultations observed, respectively. Although 14 new family planning clients were informed about the condom, the penis anatomical model was used in only two of the observed consultations. Most service providers and clinic practitioners interviewed said that they found it difficult to use the penis model during counseling sessions. During the exit interviews, clients were asked whether they had ever taken home any educational materials from the clinics and the vast majority said no. This was not surprising given that the program has very few if any IEC materials to give to clients.

\section{d) Managing clients with STDs and HIVIAIDS}

The practitioners working in the project clinics are expected to follow the national STD treatment guidelines when assessing and treating clients with symptoms suggesting STDs $^{9}$ 
Practitioners participating in the case study were asked to list the questions that they ask clients presenting with vaginal discharge to decide the possible causes of the discharge. Figure 17 shows that over half the practitioners said that they would ask about the characteristics of the discharge (duration, odor, color and consistence) while fewer than half said that they would ask about risk factors for STDs. The data suggest that practitioners are more concerned with describing the syndrome rather than identifying the possible causes and associated risk factors. The findings also suggest that practitioners are either not aware or just do not follow the available guidelines on history taking for clients with STDs.
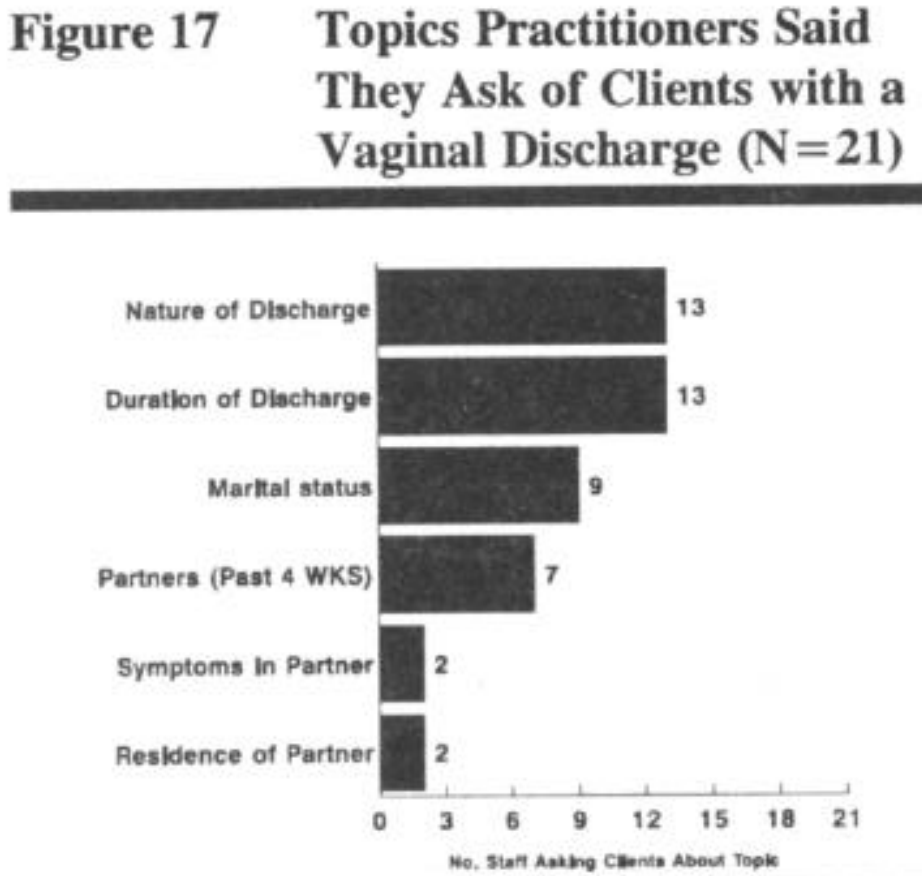

Practitioners at the 17 clinics surveyed were asked to list the drugs they use to treat clients presenting with the common STD syndromes. The responses from the service providers were compared with the treatment recommended in the National Guidelines. Most practitioners at the clinics do not follow the recommended treatment for clients with STDs. none of the practitioners interviewed mentioned any of the drugs recommended for treating clients with a urethral or cervical discharge due to gonorrhea. There are two possible explanations for these findings. The service providers may not be aware of the recommended drugs and/or they are aware but these drugs are not available within the clinics. During discussions with the project manager. she pointed out that the program cannot afford to purchase the drugs recommended by the national STD/AIDS Control Program.

The project management and practitioners felt that the cost of the recommended drugs was beyond what the project could charge without losing its clients. At the time of the case study clients were paying UGSHS. 5000.00 (S\$ 5.0) to receive STD treatment at the clinics an amount many could not afford. The other problem pointed out by the project manager was that while FLEP was responsible for family planning, STD and HIV/AIDS services in the clinics, the responsibility for purchasing drugs used for curative services including STDs was within another department of the MSRDP. This made it difficult for FLEP to coordinate the distribution and availability of drugs for treating STDs. At the time of the case study FLEP had just managed to get some limited funding from the Japanese Embassy in Uganda for the purchase of drugs that would be used to treat STDs only. The management was in the process of identifying the drugs based on the recommendations from the national STD/AIDS Control Program and the ability of clients to pay. Clients' ability to pay for the drugs is important as the project intends to sell them at a small fee to sustain the supplies. The information on clients' ability to pay is anecdotal and requires verification. 


\section{e) Contact tracing and follow-up}

The National Guidelines on STD management ${ }^{10}$ recommend that all sexual contacts of the index person diagnosed with STD infection be examined and treated simultaneously. It is also recommended that all sexual contacts during the month before diagnosis should be notified by the patient or clinician and requested to attend for STD screening and treatment despite the presence of symptoms or not in the contact. The project has attempted to carry out partner notification and follow-up of STD clients using the clients and/or VHWs with little success.

During the guided group discussions and interviews with the VHWs several possible reasons for the poor success with partner notification were cited. Culturally women are not expected to initiate discussions about sex and any related matters. This makes it difficult for women to inform their partners about STDs especially if the woman is the index person. Many (45\% and 50\%) of the 117 women interviewed said that they feel uncomfortable discussing STDs and sexual behaviour, respectively, with their spouses. These data suggest that many women probably could not notify their partners if they were found to have an STD. The VHWs also said that partner notification in polygamous unions is a problem for both the men and women. Another problem mentioned was that some village health workers are related in one way or another to the clients that they provide services to which makes it difficult for them to talk on matters related to sex especially STDs.

Although the objective of the project is to carry out STD/HIV risk assessment and screening for each MCH/FP client, findings from this study show that this is not always the case. The possible explanations include inadequate training of staff in these procedures, unavailability of appropriate guidelines, inattention of the project to cultural factors which impede implementation and inaccurate perceptions of the clients' and community situations by the service providers. Although the draft guidelines for STD and HIV/AIDS management prepared by the Ministry of Health have been available since 1993, few practitioners in the project were aware of their existence. This may also explain why many practitioners in the project were not following the recommendations in these guidelines when providing STD and HIV/AIDS services. 


\section{Need for contraceptive services among MCH clients}

Understanding clients'family planning needs:

Figure 18 shows that information necessary for identifying clients' family planning needs was asked about by the practitioners and/or volunteered by the clients in fewer than half the consultations observed. However, the observers felt that there was an established immediate need for family planning services for 23 of the $\mathrm{MCH}$ clients observed. Some action to respond to the clients' family planning needs was taken for only nine of these clients. Three of them were provided with IEC and counseling only while six were given an appointment to return to the clinic another day. Since the observer was not expected to interview the practitioners or client during the consultation, the study could not establish why the other clients with contraceptive needs were not provided with the service.
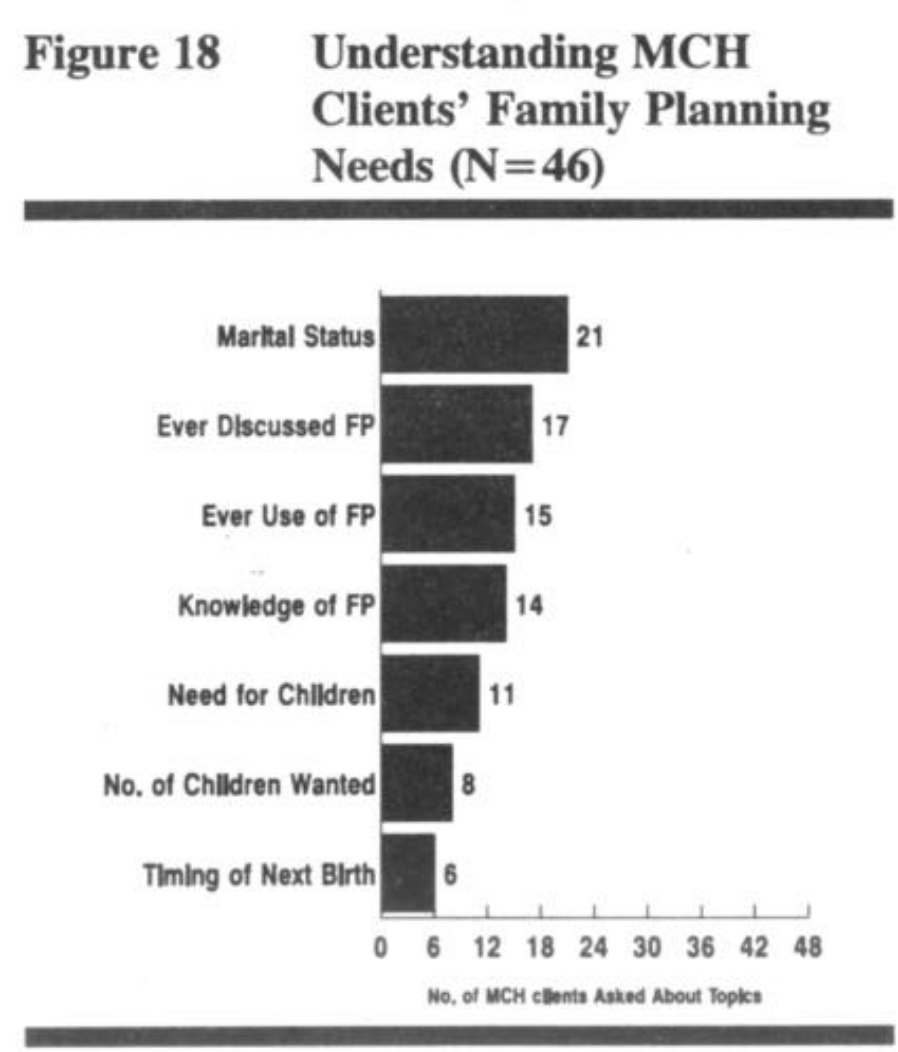

Contraceptive practices and needs of MCH clients: All 79 women seeking MCH services were asked about their contraceptive practices and reproductive intentions during the exit interviews. About one-third said that they had ever used modern contraception. Nineteen percent of the MCII clients said that they did not want to have any more children in the future. Many (55\%) of the clients who said that they would like to have a child in the future wanted to wait for another two years. These data show that $75 \%$ of women receiving $\mathrm{MCH}$ services from the clinics would like to prevent or delay the next pregnancy.

Informing MCH clients about family planning services: More than two-thirds (78\%) of the $\mathrm{MCH}$ clients interviewed said that they had seen and/or heard about family planning during their clinic visit on the day of the study. The vast majority (89\%) had seen a poster while 67 $\%$ had heard of family planning during a group health talk and $74 \%$ were informed during the consultation with the practitioners. The findings from this study show that the project is reaching many $\mathrm{MCH}$ clients with messages on family planning. 
Knowledge of symptoms associated with

STDs and HIV/AIDS: Most of the 117 women Symptoms Associated with interviewed $(87 \%)$ knew of at least one disease transmitted through sexual intercourse. All MCH/FP clients were asked spontaneously to mention all the symptoms that they knew were associated with sexually transmitted diseases. Apart from weight loss, diarrhoea of long the high percentage of clients aware of the most common symptoms and signs of HIV/AIDS compared with those aware of symptoms associated with other STDs. These findings suggest that women attending the clinics need to he educated and counselled about STDs to improve on their ability to recognize symptoms associated with STDs and to seek medical care.

History of STD related symptoms: After the clients had mentioned all the symptoms and signs that they knew, the interviewer described each symptom and then asked the client if then had experienced such a symptom in the twelve months before this study. Apart from lower abdominal pain reported by more than half the women, fewer than one-third said that they had experienced any of the other symptoms (Figure 20). These data show that many women attending the clinics have experienced some symptoms possibly suggesting STDs. However, these findings also suggest that women do not volunteer their STD history and for this information to be obtained they have to be asked about the presence of these symptoms routinely.
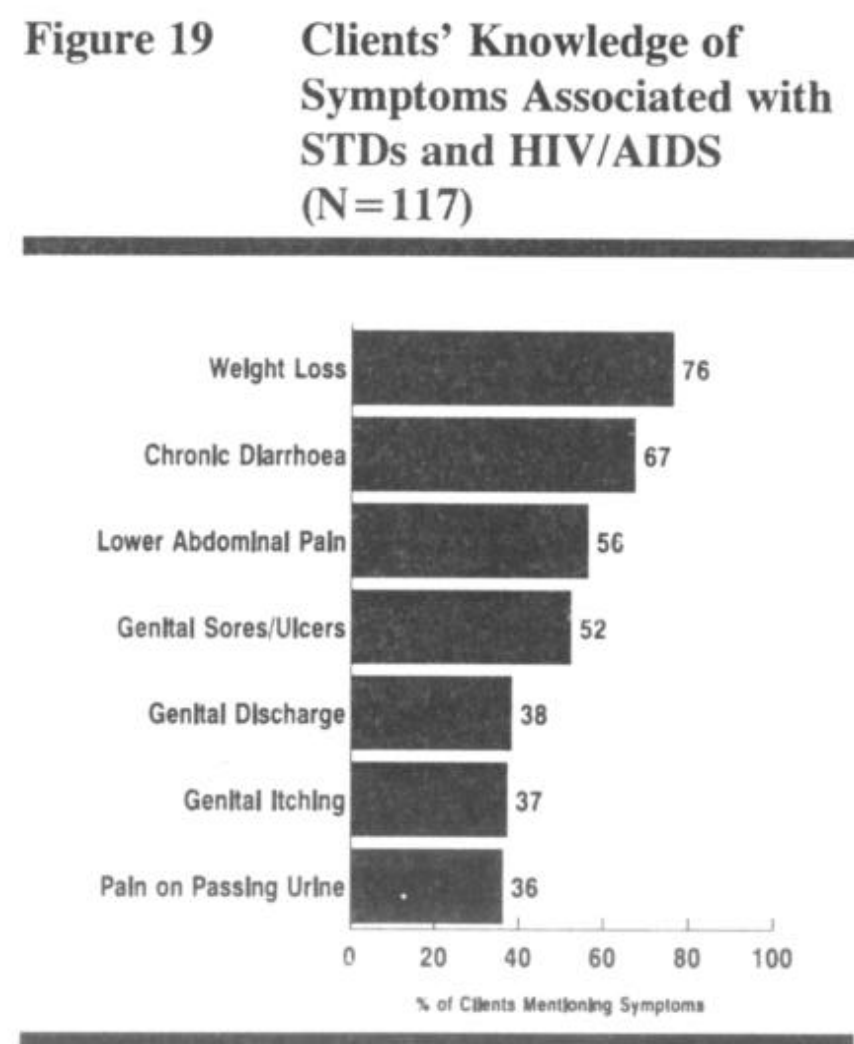

Figure 20

History of STD Related Symptoms Reported by Clients $(\mathrm{N}=117)$

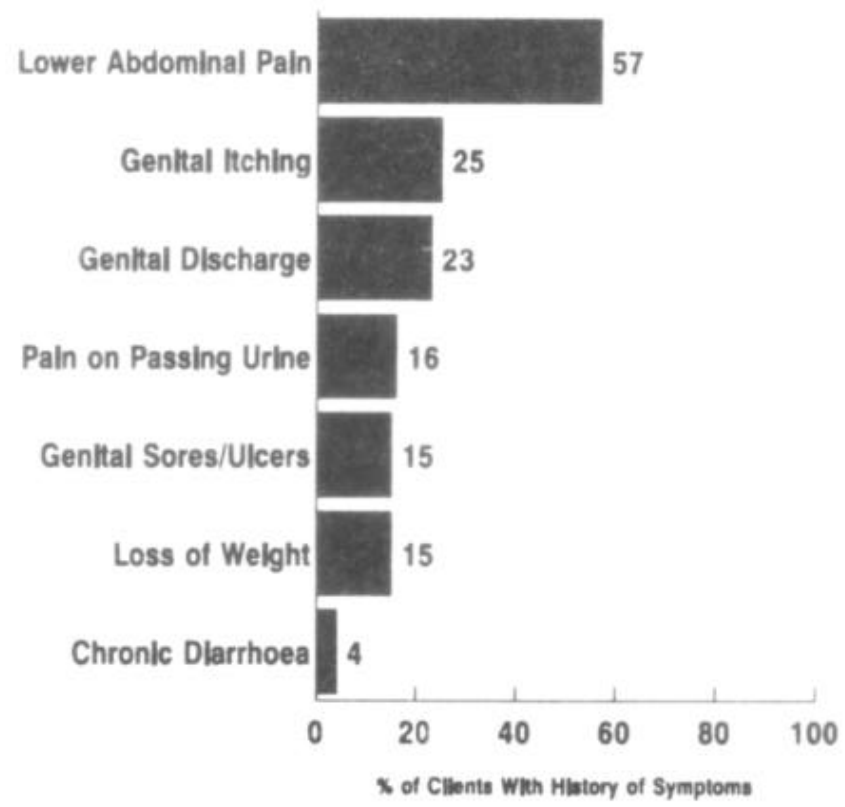


transmission of HIV: The $80(68 \%)$ women who said that they knew of other ways that HIV infection can be transmitted were asked to spontaneously name those ways. Blood transfusion was mentioned by $29 \%$, sharing contaminated instruments by $91 \%$ and mother to baby by only $14 \%$. The small number of women mentioning that they could infect their babies through transplacental transfusion or breast-feeding is worrisome. These data suggest that there is a need to review the information given to clients to include all aspects of STDs and HIV/AIDS if the program is going to make a difference to the epidemic.

Clinical evidence of STD related symptoms: The trained observer was asked to note whether there were any findings during the consultation and/or examination to suggest that the client had any symptoms and/or signs suggesting an STD. In the presence of such findings the observer recorded what action the provider took. Besides listening and observing during the consultation, the observer reviewed the client record card to make sure that they did not miss any relevant information. During the 66 consultations observed there were 18 (27\%) clients who had symptoms and/or signs suggesting STD infection. For 13 of the clients with symptoms and/or signs the service provider used the syndromic approach to make a diagnosis and decide treatment. All the 13 women were treated for pelvic inflammatory disease (PID). The remaining five clients were referred to another facility for further investigation and treatment. Only three of the 13 clients treated for STDs were advised on partner notification by the service provider.

Self risk assessment All clients interviewed were asked if they perceived themselves to be at risk of getting RJV/AIDS. More than half of the 117 women interviewed believed that they were at risk for IIIV/AIDS. The majority (93\%) of these 61 women said that they were not sure of their partners' sexual behaviour. None of the clients considered their own sexual behaviour as responsible for the increased risk status. Few clients (10\%) mentioned other risk factors like blood transfusion and use of contaminated instruments in hospitals and hair salons. These data show that many women receiving services from the clinics perceive themselves to be at risk for HIV/AIDS and therefore need to be educated and counselled on how to protect themselves. The data also suggest that the project has to find ways of reaching men who the women interviewed blame for their increased risk for HIV/AIDS.

Communicating about sexual behaviour, STDs and HIVIAIDS: Although the majority (76\%) of the practitioners interviewed said that they felt comfortable discussing issues related to sex, STDs and HIV/AIDS with their clients, this was not so with clients. Only $40 \%$ and $37 \%$ of the clients said that they were comfortable discussing their sexual behaviour with practitioners and the VHWs, respectively. Another 28\% and 30\%, respectively, of the clients said that they would feel somewhat uncomfortable while the rest (about one-third) said that they would definitely feel uncomfortable.

Just over half the clients said that they would be comfortable discussing about STDs with the practitioners and VHWs. The rest of the clients expressed varying degrees of discomfort. These findings suggest that many clients are not comfortable discussing their sexual behaviour and STD history with the service providers. This may be so because the service providers and VHWs are all members of the same community and some are related in one or another. Therefore, clients may not feel comfortable discussing about their sexual 
behavior and STDs fearing that the service providers may divulge this information to their relatives and other members of the community. This fear is supported by findings from the guided discussions with service providers during this study. During one such guided group discussion the VHWs said that sometimes not revealing some privileged information they get from their clients was difficult. For example one VHWs asked "what does society expect her to do when she sees one of her HIV positive clients seducing a close relative?" All the VHWs participating in the group discussion agreed that in such cases one has no choice but "save" the life of their relative by informing them of the status of the client and the risks involved in the relationship.

\section{Effect of adding STI and HIV/AIDS service to MCH/FP services}

The practitioners and VHWs were asked to comment on the effect of adding STD and HIVIAIDS services to the existing MCH/FP services Most of the practitioners and all the VHWs interviewed (12) said that they had noticed an increase in the number of clients seeking MCH/FP services and an improvement in the quality of services provided to clients following the addition of STD and HIV/AIDS services to the program package. A secondary analysis of the service statistics between 1992 and 1995 by REDSO showed that there had been an overall increase in CYPs generated by the project.

All clients interviewed were asked to comment on the time they had spent waiting at the clinic before being served and that spent consulting with the service provider. Most (78 $\%)$ said that the waiting time was about right while only (14\%) said that it was too long; $9 \%$ felt that waiting time was shorter than expected. When asked about the consultation time, $85 \%$ said that the time was about right while $15 \%$ felt the consultation time was too short and $9 \%$ felt it was too long. Although some practitioners (8) felt that clients' waiting and consultation times at the clinic increased because of adding STD and HIV/AIDS services to the existing services, these data show that most of the clients felt that these times were reasonable.

Many clients coming in for MCH/FP services are now able to receive STD and/or HIV/AIDS treatment and counselling at the same time. Although only one client said that the main reason for her visit to the clinic was to receive STD treatment during the exit interviews, another 18 clients were found to have symptoms and signs suggesting that they may have an STD during the consultation. These findings show that using the integrated approach helps to identify and provide STD treatment to women who did not come because of symptoms but had come for other services. 


\section{Impact of Study}

The Busoga Diocese of the Church of Uganda has taken a major step in responding to clients' reproductive health needs through FLEP. The project has shown that using simple rural-based health facilities and volunteer community-based workers to provide family planning and STD/HIV services using the integrated approach is possible. However, data from this study show that there is a considerable amount work to be done before the project will be able to provide high quality MCH/FP and STD/HIV services to every client using the integrated approach. The more pertinent observations made about FLEP are presented below:

- The existing physical facilities, space allocation and use do not allow for adequate privacy when practitioners are providing MCH/FP and STI/HIV services to clients at many facilities.

Although the communities are being helped to construct more modern facilities, it will take sometime time before most of the communities have well designed facilities that will provide adequate privacy and good client flow. The management of FLEP provides a basic plan, iron sheets and cement to be used for constructing the clinic facilities while the community provides manual labour, bricks and any other resources that are within their means. However, the health subcommittees decide on the final design of the structures taking into account what the committee considers as the communities' priority needs and what they can afford. Sometimes the final structures are in conflict with the original design making it difficult to facilitate privacy and good client flow. Once the community has completed the construction it is difficult to convince them to make alterations necessary for the provision of good quality STD and HIV/AIDS services.

Using information from the ease study, the management of FLEP initiated awareness campaigns and discussions with the health subcommittees and community leaders about the need to construct physical structures that will enhance privacy and good client flow. Some of communities have already accepted and are making structural adjustments to the clinics to respond to this new requirement. The health subcommittees were also approached and informed about the importance of advertising the services available at their clinics. This is beginning to bear fruit as already some clinics now have billboards announcing the availability of STD, HIV/AIDS, MCH, FP and other curative services.

\section{- Many clinics lack the basic equipment required to provide good quality MCH/FP services.}

The addition of STD/HIV services with the extra clinical procedures required for these services will further strain the limited equipment and supplies. Acquisition of additional equipment and supplies requires resources that are often not available and/or budgeted for when programs adapt an integrated approach. This is the case with FLEP. Without the additional equipment and supplies it will continue to be difficult for FLEP to implement the proposed integration model. 
Some of the findings from the case study have been used by the project management to identify its requirements and approach donors and friends for assistance. Pathfinder International has already responded by providing additional equipment including weighing scales, blood pressure machines and speculums to the clinics. Six clinics have been provided with EPI refrigerators by the ministry of Health to facilitate the provision of child welfare services on a daily basis. All clinics now have disposal pits that are well constructed and maintained. The clinic practitioners have been helped to adapt containers that are readily available for disposing of contaminated sharp instruments.

- Although the project has developed drama and songs for use to educate the community, these are not suitable for individual counselling and the need for other materials will continue to exist.

Most of the clinics and VHWs did not have an adequate supply of IEC materials to use when informing, educating and counselling clients about STDs and HIV/AIDS. The program also lacked materials to give to clients to carry home for further reference. Several practitioners expressed difficulty in using some of the available IEC materials like the wooden penis model due to cultural concerns.

The FLEP with assistance from the DISH project has acquired more written materials for use in informing, educating and counselling clients about STDs; HIV/AIDS, MCH and family planning services.

- At the time of the study very few of the clinics had any of the drugs recommended by the National STD/AIDS Control Program for treating STDs in stock. The practitioners at most clinics were using alternative medications that were available and affordable for the clients.

The drugs recommended by the National STD/AIDS Control Program are expensive and the program could not afford to stock them. Purchase of drugs to be used for the treatment of STI and/or HIV/AIDS is not the responsibility of FLEP. The health subcommittees purchase all the drugs for the clinics based on advice from the practitioner and the resources available to them. The inadequate resources and inability of clients to pay has greatly limited the range of available drugs to be used by the practitioners.

The Japanese Embassy made some money available to the program to be used in purchasing STD drugs using a revolving fund approach. Drugs for treating other conditions are generally lacking at these facilities, therefore providing drugs for STDs only raises several questions. The project is asking practitioners to adapt the integrated approach in providing services when providing drugs for only one condition. This sends a contradictory message to the practitioners and clients.

- Although most of the clink-based staff and VHWs have been trained in the provision of MCH, FP, STI and HIVIAIDS services, many showed a lack of internalization of skills, principles, favourable attitudes/practices and support mechanisms required to carry out FLEP's integration model. 
The study found that staff have not been trained in all aspects of the model. Although the program managers could articulate the model, they had not documented the proposed activities and made copies available to the service providers. Apart from the checklist available to practitioners there were none for use by the VHWs. Staff were found to have their own beliefs and practices about STD, HIV/AIDS and family planning services that do not help in the implementation of the integration model adapted by FLEP. The data also suggest that practitioners lack communications skills that are required to inform, educate and counsel clients about STDs and HIV/AIDS.

The FLEP has responded to some of these gaps by adapting the training curriculum revised by the DISH project. The DISH project has improved on FLEP's training curriculum using some of the findings from the case study. The curriculum now covers a wider range of topics relevant to integration. FLEP has used it for the two update courses organized for its staff in March and August 1996.

Refresher training for practitioners in ANC and CWF services has started with assistance from the DISH project At the time this report was prepared seven providers had benefited from this arrangement.

Besides reviewing its training activities, the project has created another staff category called VHW supervisors. These are long-serving VHWs who have been trained in supervision techniques and provided with a supervision checklist developed by the DISH project using some of the case study findings. Every nine-to-twelve VHWs are now supervised by two supervisors. This arrangement has removed a major time consuming activity from the practitioners leaving them with more time to attend to clients.

- The addition of STO and/or HIVIAIDS to the services provided by the FLEP has created a unique situation. AH the fleld project staff are recruited from the communities in which they have to work. Given the set up in Uganda, people of the same ancestry live together meaning that the staff would be related to some of the clients they have to serve.

This has created a problem for the VHWs and practitioners in providing STI and/or HIV/AIDS services. They find it difficult to ask their relatives questions about sexual behaviour that would help in risk assessments. In cases where courage is gathered and the questions asked, the responses given by the clients may not be the truth due to a fear that she is informing someone who may be her relative or related to her spouse.

\section{- The Ministry of Health has not yet finalized and published the draft guidelines for} the management of STI and/or HIV/AIDS.

This has made it difficult for the project to standardize its management protocols. Meanwhile the project has started using the service provider guidelines prepared and distributed by the DISH project. 
- Increases in workloads without adequate compensation is affecting the morale of the service providers.

As more demands are placed on the VHWS, they are asking for compensation for their time. They argue that they now have less time to take care of their personal and family needs at home. This is a difficult issue to deal with since most donors are not in favor of compensating VHWs for the time they put into projects. The current major donor to FLEP has been considering withdrawing some allowances provided to the VHWS. Some of the practitioners are already leaving the project due to the poor renumeration for other employers.

- The lack of access to a reliable testing facility not only for HIV but other STIs remains a problem for the project.

Data from the study show that many clients received information on other reproductive health

This has made some clients lose confidence in -the clinic facilities. The project is considering setting,.-up satellite testing' centers within the project area where rapid testing procedures will be used. How6ver this requires recruiting more staff members and training professional counselors to man these centers yet funds are limited.

- The sociocultural barriers that exist within the community have hampered contact tracing and promotion of dual contraception.

Women are not expected to initiate any discussions about sexual matters with their partners. Many of the women interviewed said that they feel uncomfortable discussing about sexual behavior and STDs with their spouses. In a program like FLEP where the primary contacts are women, their inability to speak with their partners on sexuality issues needs to be addressed for the STDs and/or HIV/AIDS services to have an impact.

- Adding STD and MV/AIDS services to the MCH/FP services has benefitted the program, service providers and clients in many ways.

Data from the study show that many clients received information on other issues apart from their main reason for visiting the clinics. The study also who wed that the integrated approach provided a good 'opportunity for many clients to have their other reproductive health needs identified. For example some clients who were not using family planning but were interested in spacing or avoiding a next pregnancy were identified. Many clients who had not come for STD treatment were identified to have symptoms suggesting STDs and treated. These data suggest that the integrated approach is achieving one of its major objectives of identifying and responding to other clients' reproductive health needs besides, the main reasons for visiting the clinics.

Service providers believe that integration of services has led to an increase in the workload and clients' waiting time at the clinics. However, the clients are satisfied with the services they are receiving and have no problems with the increase in waiting time. Both the 
practitioners and VHWs believe that using the integrated approach has greatly enhanced their image within the community.

- The demand for STD and HIVIAIDS services is still low in the study area

Most of the clients interviewed had poor knowledge about the symptoms, signs and modes of transmission for STDs and HIV/AIDS. Therefore they are not likely to recognize when they have an STD and seek treatment. Apart from poor knowledge, many of the clients said that they felt uncomfortable discussing about sexual behaviour and STDs with the project staff. This will also discourage them from seeking information and care for STDs.

- The FLEP is currently developing an Operations Research study to test out various ways of creating demand and community support for the integrated reproductive health services.

During a two day workshop organized jointly with The Population Council, Pathfinder International and REDSO/ESA, project staff reviewed the findings from the case study and developed a 'results framework' and a possible plan of action. The 'results framework' was based on the project staff's understanding of the Mission of FLEP and the reasons for adapting the integrated approach to provide STDs, HIV/AIDS and MCH/FP services.

Using the 'results framework', findings from the case study and their experiences in the field project staff identified and priotized issues they felt needed to be addressed if the project was to achieve the immediate results outlined in the 'results frame-work'. Ten major issues were identified by the staff and prioritised using a weighting scheme.

The management of FLEP with assistance from staff from the DISH project and The Population Council used the list of issues generated by the project staff to identify two operations research activities that could be carried out in the next two years. The Population Council will continue to assist FLEP in developing project proposals for these two activities. It is hoped that funding will be obtained from REDSO to carry out one or both of these research activities.

The study concluded that although the implementation of FLEP's integration model is still in its infancy, important achievements have been made that both the service providers and clients can identify with. These achievements have been made under considerable constraints of funding, human resources and experience regarding good integration models. The process also provides several lessons for other programs initiating similar activities. 
$2 n$ 